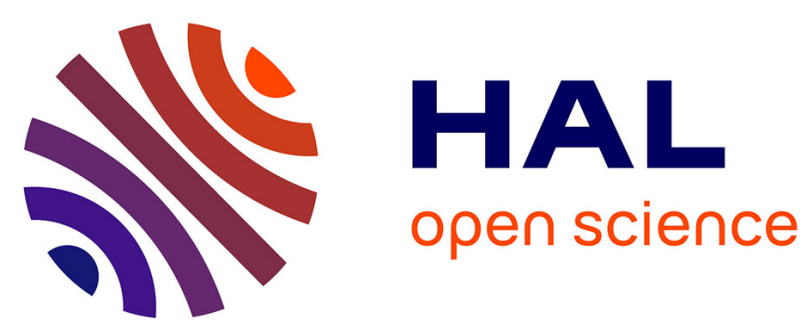

\title{
Optimal heat and electric power flows in the presence of intermittent renewable source, heat storage and variable grid electricity tariff
}

Getnet Tadesse Ayele, Mohamed Tahar Mabrouk, Pierrick Haurant, Björn Laumert, Bruno Lacarrière

\section{To cite this version:}

Getnet Tadesse Ayele, Mohamed Tahar Mabrouk, Pierrick Haurant, Björn Laumert, Bruno Lacarrière. Optimal heat and electric power flows in the presence of intermittent renewable source, heat storage and variable grid electricity tariff. Energy Conversion and Management, 2021, 243, pp.114430. 10.1016/j.enconman.2021.114430 . hal-03271734

\section{HAL Id: hal-03271734 \\ https://hal.science/hal-03271734}

Submitted on 27 Jun 2021

HAL is a multi-disciplinary open access archive for the deposit and dissemination of scientific research documents, whether they are published or not. The documents may come from teaching and research institutions in France or abroad, or from public or private research centers.
L'archive ouverte pluridisciplinaire HAL, est destinée au dépôt et à la diffusion de documents scientifiques de niveau recherche, publiés ou non, émanant des établissements d'enseignement et de recherche français ou étrangers, des laboratoires publics ou privés. 


\title{
Optimal Heat and Electric Power Flows in the Presence of Intermittent Renewable Source, Heat Storage and Variable Grid Electricity Tariff
}

\author{
Getnet Tadesse Ayele ${ }^{a}$, Mohamed Tahar Mabrouk, ${ }^{b}$ Pierrick Haurant ${ }^{b}$, Björn Laumert and Bruno Lacarrière $^{b}$ \\ ${ }^{a}$ Faculty of Electrical and Computer Engineering, Bahir Dar Institute of Technology, Bahir Dar University, P.O. Box 26 \\ Bahir Dar, Ethiopia \\ ${ }^{b} I M T$ Atlantique, GEPEA, UMR CNRS 6144, F-44307 Nantes, France. \\ ${ }^{c}$ Department of Energy Technology, KTH Royal Institute of Technology, 10044 Stockholm, Sweden. \\ agetnet.tadesse@bdu.edu.et (CA)
}

\begin{abstract}
To decarbonize and increase the flexibility in the heating and electricity sectors, large heat pumps, combined heat and power plants, renewables and storage technologies are increasingly being installed. This results in a tighter coupling between the electricity and heat distribution networks. Hence, the two networks need to be operated in an integrated way so that their synergies can be exploited. The main challenge in that regard is the lack of suitable tools that can capture the detailed operating parameters of both networks simultaneously. This paper proposes a population-based optimal power flow model for integrated heat and electricity distribution networks. An extended energy hub approach is used to model the components of the integrated energy system in a modular form. Active and reactive power balances, heat power balance and optimal management of storage technologies in the presence of intermittent renewables and variable tariffs are considered. The proposed method is then tested using a case study of highly coupled electricity and heat distribution networks consisting of a heat pump, a gas boiler, a combined heat and power plant, a wind turbine and a thermal storage together with a variable electricity tariff. It is found that above $97 \%$ of the surplus production from the wind power plant is effectively used in the system and $10.35 \%$ of the heat demand is effectively shifted from the peak hours to the cheap-electricity hours. The results show that the proposed method can be used as a decision support tool that can be used for the optimal integration of heat and electricity distribution networks. It also maximizes the synergy that can be captured from the multienergy systems in general and from the heat and electricity distribution networks in particular.
\end{abstract}

Keywords: An extended energy hub; Coupled electricity and heating networks; Integrated load flow model; Multicarrier optimal power flow; Multi-energy system; Optimal heat and electric power flows. 


\section{Nomenclature}

\section{Abbreviations and acronyms}

$\begin{array}{ll}\text { AC } & \text { Alternating current } \\ \text { CHP } & \text { Combined heat and power } \\ \text { COP } & \text { Coefficient of performance of a heat pump } \\ \text { DC } & \text { Direct current } \\ \text { DHN } & \text { District heating network } \\ \text { EEH } & \text { Extended energy hub } \\ \text { HP } & \text { Heat pump (compression type) } \\ \text { MES } & \text { Multi-energy system } \\ \text { MPC } & \text { Model predictive control } \\ \text { PSO } & \text { Particle swarm optimisation } \\ \text { pu } & \text { Per-unit }\end{array}$

\section{Latin symbols}

\begin{tabular}{|c|c|}
\hline$A_{c}$ & Cross-section area of a thermal storage water tank $\left[\mathrm{m}^{2}\right]$ \\
\hline$A_{s 1}, A_{s 2}, A_{s 3}$ & Lateral surface areas of layer 1 , layer 2 and layer 3 of a stratified thermal storage $\left[\mathrm{m}^{2}\right]$ \\
\hline$C_{\delta(\gamma)}$ & $\begin{array}{l}\text { An element in a coupling matrix showing how much of the input power of type } \gamma \text { is converted } \\
\text { into the local demand type of } \delta\end{array}$ \\
\hline$C_{l o c}$ & A fraction to take the local pressure losses due to valves and junctions into account \\
\hline$C_{p}$ & Specific heat capacity of water $\left[\mathrm{J} \cdot \mathrm{kg}^{-1} \cdot \mathrm{K}^{-1}\right]$ \\
\hline$C_{P e l g}$ & Cost of electricity solely generated $[€ / \mathrm{h}]$ \\
\hline$C_{P e l(1)}$ & Cost of imported/exported electricity through the slack hub $[€ / \mathrm{h}]$ \\
\hline$C_{P f g}$ & Cost of fuel used in the system $[€ / h]$ \\
\hline$C_{P h g}$ & Cost of heat solely generated $[€ / \mathrm{h}]$ \\
\hline$C_{P h(1)}$ & Cost of imported/exported heat through the slack hub $[€ / \mathrm{h}]$ \\
\hline$\dot{E}_{h}$ & A rate of change of stored thermal energy in a hot water storage tank [W] \\
\hline $\mathcal{F}$ & Objective function of an optimization \\
\hline$g$ & Gravitational acceleration $\left[\mathrm{m} . \mathrm{s}^{-2}\right]$ \\
\hline$H$ & Hydraulic head $[\mathrm{m}]$ \\
\hline$I$ & Current flow $[\mathrm{A}]$ \\
\hline$I_{\max }$ & Ampacity of a transmission line $[\mathrm{A}]$ \\
\hline$k_{i j}$ & Pressure resistance coefficient for the pipe flow connecting nodes $i$ and $j\left[\mathrm{~m} . \mathrm{s}^{2} \cdot \mathrm{kg}^{-2}\right]$ \\
\hline$K_{S}$ & Heat loss factor of the thermal storage water tank $\left[\mathrm{W} \cdot \mathrm{m}^{-2} \cdot \mathrm{K}^{-1}\right]$ \\
\hline$k_{w}$ & Thermal conductivity of water $\left[\mathrm{W} \cdot \mathrm{m}^{-1} \cdot \mathrm{K}^{-1}\right]$ \\
\hline$L$ & Length of a branch (transmission line or pipe) [m] \\
\hline$L_{e p}$ & Active electric power demand $[\mathrm{W}]$ \\
\hline$L_{e p}^{H P}$ & Active electric power consumed by a heat pump [W] \\
\hline$L_{e q}$ & Reactive electric power demand [var] \\
\hline$L_{e q}^{H P}$ & Reactive electric power consumed by a heat pump [var] \\
\hline$L_{h}$ & Heat power demand [W] \\
\hline$\dot{m}$ & Mass flow rate from a hub to a node $\left[\mathrm{kg} . \mathrm{s}^{-1}\right]$ \\
\hline$\left|\dot{m}_{\text {con }}\right|$ & Magnitude of mass flow rate on the primary side of the substation $\left[\mathrm{kg} . \mathrm{s}^{-1}\right]$ \\
\hline$\dot{m}_{i j}$ & Pipe mass flow rate from node $i$ to $j\left[\mathrm{~kg} \cdot \mathrm{s}^{-1}\right]$ \\
\hline
\end{tabular}




\begin{tabular}{|c|c|}
\hline$\dot{m}_{\max }$ & Maximum acceptable pipe flows $\left[\mathrm{kg} \cdot \mathrm{s}^{-1}\right]$ \\
\hline$m_{1}, m_{2}, m_{3}$ & Mass of water in layers 1,2 and 3 of a stratified thermal storage $[\mathrm{kg}]$ \\
\hline$P_{\text {el(pumping })}$ & Active electricity consumed by a circulation pump [W] \\
\hline$P_{e p}$ & Electrical active power injected into the network [W] \\
\hline$P_{e p}^{C H P}$ & Electrical active power produced by a combined heat and power plant [W] \\
\hline$P_{\text {ep_in }}$ & Electrical active power flowing into the coupling system of an energy hub [W] \\
\hline$P_{\text {epg }}$ & Electrical active power solely generated [W] \\
\hline$P_{\text {epg(wind })}$ & Electrical active power generated from the wind turbine $[\mathrm{W}]$ \\
\hline$P_{e q}$ & Electrical reactive power injected into the network [var] \\
\hline$P_{e q}^{C H P}$ & Electrical reactive power produced by a combined heat and power plant [var] \\
\hline$P_{\text {eq_in }}$ & Electrical reactive power flowing into the coupling system of an energy hub [var] \\
\hline$P_{\text {eqg }}$ & Electrical reactive power solely generated [var] \\
\hline$p f$ & Power factor \\
\hline$P_{f_{-} i n}$ & Fuel power flowing into the coupling system of an energy hub [W] \\
\hline$P_{f g}$ & Fuel power generated $[\mathrm{W}]$ \\
\hline$P_{h}$ & Heat power injected into the network [W] \\
\hline$P_{h}^{\text {Boiler }}$ & Heat power produced by a boiler [W] \\
\hline$P_{h}^{C H P}$ & Heat power produced by a combined heat and power plant [W] \\
\hline$P_{h}^{\text {discharged }}$ & Heat power discharged from a thermal storage $[\mathrm{W}]$ \\
\hline$P_{h}^{H P}$ & Heat power produced by a heat pump [W] \\
\hline$P_{h}^{\text {storage }}$ & Heat power flowing to/from a thermal storage $[\mathrm{W}]$ \\
\hline$P_{h}^{\text {stored }}$ & Heat power flowing into a thermal storage [W] \\
\hline$P_{h \_ \text {in }}$ & Heat power flowing into the coupling system of an energy hub [W] \\
\hline$P_{h g}$ & Heat power solely generated [W] \\
\hline$R_{o}$ & Outer radius of an outer jacket of a pipe in a district heating network [m] \\
\hline$R_{\text {storage }}$ & Radius of a cylindrical thermal storage water tank [m] \\
\hline$t$ & Time $[\mathrm{s}]$ \\
\hline$T$ & Temperature $[\mathrm{K}]$ \\
\hline$T_{a(t)}$ & Ambient (soil) temperature at time $t[\mathrm{~K}]$ \\
\hline$T_{r(\max )}$ & Maximum return temperature limits at heat-sink hubs $[\mathrm{K}]$ \\
\hline$T_{r(\min )}$ & Minimum return temperature limits at heat-sink hubs $[\mathrm{K}]$ \\
\hline$T_{s(\max )}$ & Maximum supply temperature limits at heat-source hubs $[\mathrm{K}]$ \\
\hline$T_{s(\min )}$ & Minimum supply temperature limits at heat-source hubs $[\mathrm{K}]$ \\
\hline$T_{i(p)}$ & Inlet water temperature of pipe $p[\mathrm{~K}]$ \\
\hline$T_{j(p)}$ & Outlet water temperature pipe $p[\mathrm{~K}]$ \\
\hline$T_{1(t-\Delta t)}$ & Temperatures of layer 1 of a stratified thermal storage at time $t-\Delta t[\mathrm{~K}]$ \\
\hline$T_{1(t)}$ & Temperatures of layer 1 of a stratified thermal storage at time $t[\mathrm{~K}]$ \\
\hline$T_{2(t-\Delta t)}$ & Temperatures of layer 2 of a stratified thermal storage at time $t-\Delta t[\mathrm{~K}]$ \\
\hline$T_{2(t)}$ & Temperatures of layer 2 of a stratified thermal storage at time $t[\mathrm{~K}]$ \\
\hline$T_{3(t-\Delta t)}$ & Temperatures of layer 3 of a stratified thermal storage at time $t-\Delta t[\mathrm{~K}]$ \\
\hline$T_{3(t)}$ & Temperatures of layer 3 of a stratified thermal storage at time $t[\mathrm{~K}]$ \\
\hline$U$ & Overall heat transfer coefficient $\left[\mathrm{W} \cdot \mathrm{m}^{-2} \cdot \mathrm{K}^{-1}\right]$ \\
\hline$V$ & Voltage [V] \\
\hline$|V|$ & Voltage magnitudes [per unit] \\
\hline$V_{\min }, V_{\max }$ & Minimum and maximum nodal voltage magnitude limits [per unit] \\
\hline$V_{\text {storage }}$ & Volume of a thermal storage $\left[\mathrm{m}^{3}\right]$ \\
\hline
\end{tabular}


$X \quad$ Reactance of a transmission line [ $\Omega]$

$Y_{i j} \quad$ An element in the admittance matrix of the electricity network

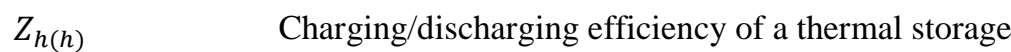

$Z_{1}, Z_{2}, Z_{3} \quad$ Heights of layer 1, layer 2 and layer 3 of a stratified thermal storage tank [m]

\section{Greek symbols}

$\begin{array}{ll}\Delta H & \text { Hydraulic head difference [m] } \\ \Delta t & \text { Time step [s] } \\ \eta & \text { Efficiency } \\ \theta & \text { Voltage angle [rad] }\end{array}$

\section{Subscripts}

$\begin{array}{ll}a & \text { Ambient } \\ b & \text { Boiler } \\ c & \text { Consumer } \\ \text { CHP } & \text { Combined heat and power } \\ e l & \text { Electrical } \\ e p & \text { Active power } \\ e q & \text { Reactive power } \\ f & \text { Fuel power } \\ g & \text { Locally generated } \\ h & \text { Heat power } \\ \text { HP } & \text { Heat pump } \\ i, j, k & \text { Numbers identifying hubs, nodes, buses } \\ p & \text { Pipe } \\ r & \text { Return pipe of a DHN } \\ s & \text { Supply pipe of a DHN } \\ t h & \text { Thermal }\end{array}$




\section{Introduction}

A multi-energy system (MES) provides a new approach to meet energy demands in an optimized way by exploiting the synergy from multiple energy sectors, such as electricity, heating, cooling and transport [1]. Such synergies are indispensable to succeed in the energy transition, which could be otherwise impossible within the limits of the individual sectors. Heat and electricity sectors that are coupled using either of the heat pumps (HPs), combined heat and power (CHP) plants or thermal storages are examples of MESs. The CHP converts any fuel into electricity and heat while the HP (compression type) converts electricity into heat. Such coupling is getting wider acceptance in Europe as a means of decarbonizing the heating and cooling sectors [2]. Countries with large shares of HPs and CHPs in their heating market, such as Sweden [3], Finland [4] and Denmark [5] have the most sustainable heating sectors in Europe [6].

Smart electric grid and $4^{\text {th }}$ generation district heating network, for instance, can be integrated using electric vehicles and hot water tanks as energy storage mechanisms resulting in up to $32 \%$ energy saving [7]. Integration of multienergy storage like electric vehicles, heat storage and cold storage can be used to achieve an energy saving of $53.5 \%$ in a nearly zero energy community [8].

Thermal storages, CHPs and HPs can also be used to increase the flexibility in the electricity and heating systems so that intermittent renewables, such as wind generations, can be effectively used [9]. Cogeneration systems consisting of energy storage technologies can also be used to exploit the cheap electricity during off-peak hours [10]. As electrical storage devices are more expensive (50 to 100 times) than thermal storage tanks [11], the latter can be used to store any surplus of electricity in the form of heat. A comparative study of solar-based energy system for net-zero buildings shows that a HP combined with heat/cold storage is more economical than a HP with electrical battery setup [12]. Though the use of thermal storage may increase distribution losses in the district heating network (DHN), the reduction in the installed capacity (peak shaving potential) and the increase in the penetration level of intermittent renewable sources weigh more [13]. It means that more renewables can be integrated in the electricity system without any curtailment; the peak heat demands can be effectively shifted; and, consequently, a more efficient, flexible and sustainable energy system can be established. Feasibility studies based on simplified models using simulation tools like EnergyPlan [14], RETScreen [15] and HOMER [16], also support these ideal premises.

However, the HPs and the thermal storages are exclusively managed by the DHN operators without considering the electricity distribution network from where the HPs are getting the electricity. This leads to a suboptimal 
operation of the electricity system. The electricity distribution company, for example, estimates the electricity demand based on its own data considering the HPs usually as fixed loads. A DHN operator, on the other hand, considers the heat demand profile and all the heat sources (including the HPs), and decides on the most economical operational strategy of the HPs. As the two distribution system operators act independently, any possible difference between the assumed and the actual operational strategy of the HPs may compromise the efficiency of the overall system [17]. Moreover, the installation of large HPs has paused a security issue as it is increasingly overloading the low voltage electricity distribution grid [18]. Besides that, an optimal placement and economical dispatch of coupling technologies, like CHPs, made exclusively from the heating network perspective, could lead to suboptimal solutions in the electricity network.

In order to have optimal overall system, operating parameters of both the electricity and heat distribution networks need to be considered in the management of coupling technologies. Such analyses are rare in literature. The simplified MES simulation tools, like HOMER [19] and EnergyPlan [14], lacks that capacity as they do not consider the distribution networks' physical and operating parameters. Neither do the conventional single-energycarrier simulation tools capture the operating parameters of the multi-carrier distribution grids [20]. The following section highlights the state of the art in tackling these challenges. The proposed methods are then discussed in Section 3. Section 4 presents a case study selected for testing the proposed methods. The results and discussions follow in Section 5. The main concluding remarks are then summarised in Section 6.

\section{Literature review on multi-carrier optimal power flow models}

In the study of multi-carrier optimal power flow, the multi-carrier load flow model is the main equality constraint. As the constituent equations of such a model are complex and highly nonlinear, it is difficult to optimise the multicarrier power flows using the deterministic and analytical approaches. Heuristic/metaheuristic optimisation techniques are more suitable to handle such highly nonlinear and nonconvex optimization problems. The advancement in the computational power of computers significantly contributed for the increasing acceptance of such techniques. Genetic Algorithm [21], Teaching Learning Based Algorithms [22], Honey Bee Mating Algorithms [23] and Particle Swarm Optimisation (PSO) [24] are some of them that are widely applied in the energy fields. To use such techniques in the study of multi-carrier optimal power flows, the load flow model of the corresponding MES needs to be formulated first. Unfortunately, there are no well-developed off-the-shelf modelling and simulation tools that can take the MES distribution networks' physical parameters into account [25]. At research level, on the other hand, two approaches of multi-carrier power flow simulations and 
optimizations are reported in literature. The first approach is based on the existing single-energy-carrier models running in a co-simulation environment while the second is based on tailor-made models.

Widl et al. [20] used DIgSILENT for electricity and Modelica for DHNs, both software running in a co-simulation environment called FUMOLA. An electric boiler is the only coupling device used. Arnaudo et al., [18] used Panda Power, Modelica and python-based models running in co-simulation platform called ZerOBNL to study the flexibility that can be gained from distributed HPs. The electricity distribution network is simulated using Panda Power and the residential buildings are modelled on Modelica. HPs, thermal storage and controllers are implemented on python. A similar study that includes DHN model is presented in [26]. In the above three papers, a sequential coupling is implemented by first running the thermo-hydraulic model of the DHN followed by the steady state simulation of the electricity distribution network. The steps are repeated until both simulations converge. The use of a well-established simulation tools, like DIgSILENT and Modelica, in a co-simulation environment enables to capture all the relevant information including the dynamics of components at very small simulation time-steps. However, the sequential iteration approach, which is efficient for load flow studies and scenario based comparative studies, has limitations in handling optimisation problems that involve coupling technologies. A CHP is a good example for this. The optimal dispatch of a CHP found by simulating the DHN will rarely be in agreement with what would be found from running the electricity distribution network optimisation. This could result into oscillating solutions without any convergence.

To overcome such challenges, varieties of tailor-made models are reported in literature. Bracco et al. [27] studied a MES consisting of CHPs, solar photovoltaics, solar thermal, absorption chillers, electrical and thermal storages to supply residential demands and electric vehicles. The demands and the energy technologies are interconnected using an electricity distribution network modelled using direct current (DC) power flow approximation. The heat distribution network is ignored totally. Similarly, renewable integration planning in urban multi-carrier energy distribution grids is discussed in [28]. The heat and electricity distribution networks are modelled using power flow balances with approximate loss functions. The approximations in both papers are acceptable only if the distribution network is small or if the reactive power flow in the system is not significant. Electrification of DHN using solar photovoltaic and HPs is studied in [29] with the focus on identification of lossy branches. The electricity demands were not taken into account, however.

Li et al. [30] studied the electricity and heating networks that are coupled using a HP. Alternating current (AC) power flow model is applied for electricity network while mass balance and temperature drops are used to model 
the heating network. However, the possibility of meshed DHN topologies is not considered. The method is improved by Awad et al. [31] and Liu et al. [32] using node-loop equations together with pseudo-dynamic temperature drop equations to model the heating network consisting of meshed loops. The node-loop equations used in the hydraulic model of the heating network, however, need pseudo-loop paths (the number of which depends on the network topology) in addition to the physical loops in order to have equal number of equations as the number of unknowns. As identification of pseudo-loops is not straight forward, it is difficult to develop a general algorithm for the models that are based on node-loop equations [33].

Liu and Mancarella [34] and Shabanpour-Haghighi and Seifi [35] extended the load flow model presented in [32] into an energy system consisting of gas, electricity and DHN. The application of such models to study network congestion and uncertainties are presented in [36] and [37], respectively. Both active and reactive power flows are considered in their case studies. However, lack of generality on the hydraulic models remained unsolved due to the use of the node-loop equations.

M. Geidl and G. Andersson [38] described a multi-carrier energy system as an interconnection of modular energy hubs. In their work, electricity, heat and gas energy carriers are considered. AC power flow equations are used to model the electricity network while hydraulic equations are assumed to represent any isothermal pipe flow networks. A similar approach that includes a thermal storage is discussed in [39]. Both papers assume unidirectional power flows into the hubs, which implicitly limits the energy hubs to act as consumers all the time. This is not always true as there could be more production of a given energy carrier inside a hub than is required by the hub itself. The hub shall have a flexibility to inject the excess power back to the network. In addition, it is not clearly defined how local generation, including renewables, are connected to the network. Furthermore, heating networks are not considered in their analysis and all the thermal demands are assumed to be met locally at each hub.

A general and flexible framework that can be used to model multi-carrier energy distribution networks using an extended-energy-hub (EEH) approach is discussed in [40]. The details of the integrated load flow model consisting of electricity and heating networks that are coupled by CHPs are discussed in particular. The methodology is further expanded to handle a pseudo-dynamic simulation in the presence of HPs and solar photovoltaics, as presented in [41]. Optimal placement of HPs and thermo-economic optimisation of coupled electricity and district heating networks are discussed in [17] and [42], respectively. Though these papers show the capacity of the EEH approach in capturing the operational parameters of coupled electricity and heating networks, their scopes are 
limited either to single-hour load flow studies and optimizations or to merit-based multiple-hour simulations. Energy storage technologies and their management strategy are not covered.

Use of heat distribution network and building thermal inertia as a storage in the presence of intermittent wind generation is discussed in [43]. However, only the heating network is considered in these studies. Demand side management using buildings' inertia and additional hot water tank as thermal storages while taking the constraints in the electrical distribution grid is presented in [18]. The paper shows that demand side management allows the installation of larger HPs without overloading the electricity distribution network. However, onsite heat supply for each building is assumed, and the heat distribution network is not considered. Furthermore, the possibility of variable electricity tariff together with intermittent renewables is not addressed in both papers.

The flexibility that can be unlocked by combining variable electricity prices, demand side management and thermal storage in the presence of intermittent solar and wind power plants is studied in [44]. The results show that HPs and electric boilers together with the thermal storage can increase the capacity of renewables that can be installed in urban energy system. However, the losses and constraints of both distribution networks are neglected which might lead to inadmissible voltage and/or temperature deviations. Moreover, an ideal thermal storage operating at constant return and supply temperatures is assumed, which is far from the reality.

The above literature survey shows the importance of thermal storages in a coupled electricity and heating networks consisting of HPs, CHPs, intermittent renewables and variable electricity tariff. These combined features, however, are not well studied in literature due to lack of suitable modelling tools. The distribution networks' parameters together with the dynamics of the thermal storage are not considered either. In addressing these scientific gaps, this paper has the following methodological contributions:

- It shows how optimal heat and electricity flows in a coupled heat and electricity distribution networks can be conducted considering the detailed parameters of the respective distribution networks.

- It illustrates how a detailed thermal storage model can be incorporated in the extended energy hub configuration

- It demonstrates how intermittent renewables and variations in tariffs can be captured using a thermoeconomic optimization so that the renewable curtailments can be reduced while increasing the flexibility in the energy system. 


\section{Mathematical models}

This paper proposes an optimization algorithm that minimizes the operating cost of highly coupled electricity and heat distribution networks while considering the detail models of the respective distribution networks. It exploits the synergy from the two networks in the presence of variable tariffs and intermittent renewables. To achieve this, a population-based optimization algorithm is incorporated with the integrated load flow model of the electricity and heat distribution networks.

\subsection{Integrated load flow model of electricity and heat distribution networks}

The EEH approach is used to model the integrated load flow problem of coupled heat and electricity networks in modular form. In this approach, a MES is modelled as an interconnection of energy hubs. The interactions between different energy carriers at each energy hub is expressed using coupling matrix, which is then linked with the power flow equations that govern each distribution network [40]. The coupling equations at all hubs together with the power flow equations give the integrated load flow model.

\subsubsection{Coupling equations}

These coupling equations, relate the inputs into the coupling system with the local demands (see examples of EEH in Fig. 1). The input power into the coupling system for a given energy carrier is the difference of the locally generated power and the power injected into the network. The general coupling equation at each energy hub with a thermal storage where fuel, electricity and heat interact is expressed using equation (1). The demands and generations are all expressed in a common per-unit (pu) system, the details of which can be referred from [40].

$$
\left[\begin{array}{c}
L_{e p} \\
L_{e q} \\
L_{h}
\end{array}\right]=\left[\begin{array}{ccccc}
C_{e p(e p)} & C_{e p(e q)} & C_{e p(h)} & C_{e p(f)} & 0 \\
C_{e q(e p)} & C_{e q(e q)} & C_{e q(h)} & C_{e q(f)} & 0 \\
C_{h(e p)} & C_{h(e q)} & C_{h(h)} & C_{h(f)} & Z_{h(h)}
\end{array}\right]\left[\begin{array}{c}
P_{e p g}-P_{e p} \\
P_{e q g}-P_{e q} \\
P_{h g}-P_{h} \\
P_{f g} \\
\dot{E}_{h}
\end{array}\right]
$$

where $C_{\delta(\gamma)}$ represents a coupling coefficient relating generation type $\gamma$ with load type $\delta ; P_{e p g}, P_{e q g}, P_{h g}$, and $P_{f g}$ are local generations of active electric, reactive electric, heat and fuel powers, respectively while $P_{e p}, P_{e q}$, and $P_{h}$ represent the active electric, reactive electric and heat power injections into the network, respectively. The term $Z_{h(h)}$ refers to the charging/discharging efficiency of the thermal storage and $\dot{E}_{h}$ is the rate of change of stored heat, which is equal to the net charging power going into the thermal storage. 


\subsubsection{Coupling equations for energy hubs with different technologies}

Fig. 1 shows examples of EEH configurations for energy hubs with a gas boiler (Fig. 1(a)), a CHP (Fig. 1(b)), a HP (Fig. 1(c)), and a thermal storage (Fig. 1(d)). The CHP in Fig. 1(a) couples the fuel, heat and electricity energy carriers while the HP in Fig. 1(b) couples only heat and electricity. A gas boiler, on the other hand, couples fuel (gas) and heat energy carriers as shown in Fig. 1(c), while the thermal storage acts as a buffer for the heat energy carrier.

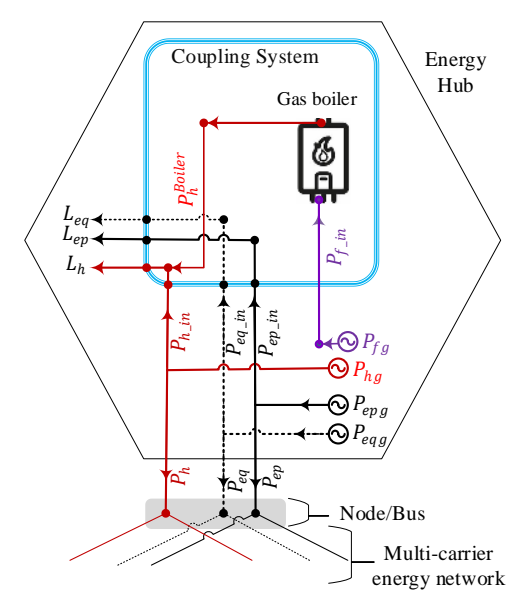

(a)

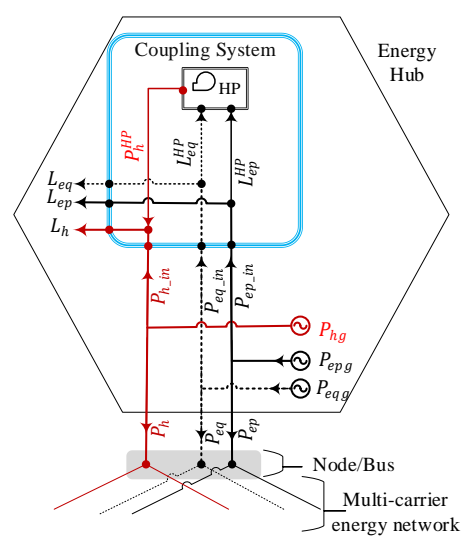

(c)

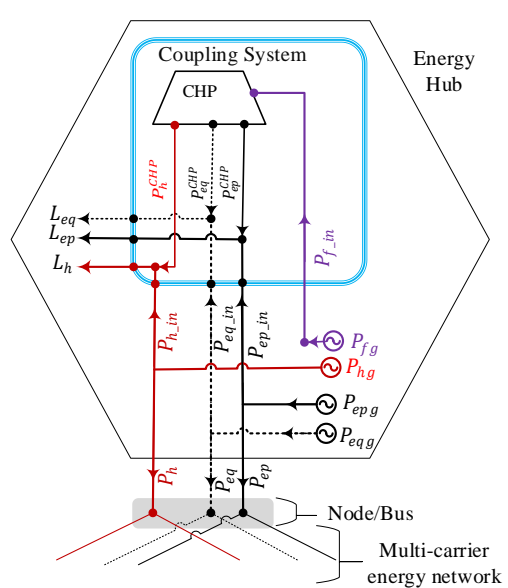

(b)

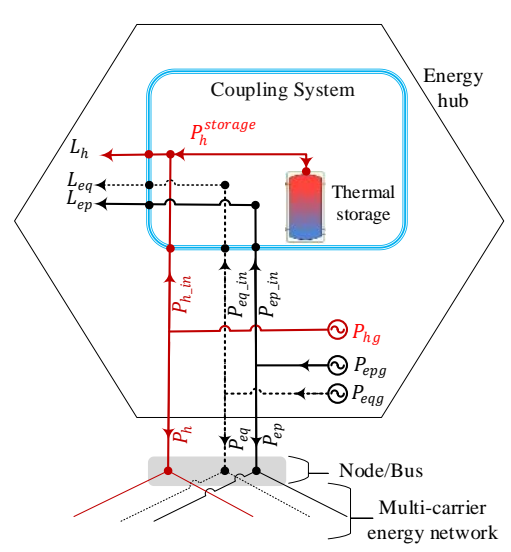

(d)

Fig. 1. Examples of energy hubs and their EEH representations showing the interactions between heat, electricity and fuel energy carriers. (a) a hub with a gas boiler, (b) a hub with a CHP, (c) a hub with a HP, (d) a hub with a thermal storage.

The terms, $P_{f g}, P_{h g}, P_{e p g}$ and $P_{e q g}$ indicate the local generations of fuel, heat, active and reactive powers, respectively. The terms $P_{h}, P_{e p}$ and $P_{e q}$ represent the heat, active and reactive power injections into the network, respectively. $P_{h_{-} i n}, P_{f_{-} i n}, P_{e p_{-} i n}$ and $P_{e q_{-} i n}$ are the heat, fuel, active and reactive power inputs into the coupling system, respectively. $L_{h}, L_{e p}$, and $L_{e q}$, denote the heat, active and reactive power demands of the energy hub. $P_{h}^{\text {Boiler }}, P_{h}^{H P}$ and $P_{h}^{C H P}$ represent the heat power outputs from the gas boiler, the HP and the CHP, respectively. The terms $L_{e p}^{H P}$ and $L_{e q}^{H P}$ represent the active and reactive electric power consumptions of the HP while $P_{e p}^{C H P}$ and $P_{e q}^{C H P}$ designate the active and reactive power generations from the CHP, respectively. $P_{h}^{\text {storage }}$ refers to the charging (negative for discharging) power flow into the thermal storage. 
The coupling equations for the energy hubs shown in Fig. 1(a) - Fig. 1(d) can be derived as shown in equations (2) - (5), respectively. In the same way, the coupling equation governing an energy hub without any coupling technology is given by equation (6).

$$
\begin{aligned}
& {\left[\begin{array}{c}
L_{e p} \\
L_{e q} \\
L_{h}
\end{array}\right]=\left[\begin{array}{cccc}
1 & 0 & 0 & 0 \\
0 & 1 & 0 & 0 \\
0 & 0 & 1 & \eta_{b}
\end{array}\right]\left[\begin{array}{c}
P_{e p g}-P_{e p} \\
P_{e q g}-P_{e q} \\
P_{h g}-P_{h} \\
P_{f g}
\end{array}\right]} \\
& {\left[\begin{array}{c}
L_{e p} \\
L_{e q} \\
L_{h}
\end{array}\right]=\left[\begin{array}{cccc}
1 & 0 & 0 & \eta_{e l} \\
0 & 1 & 0 & -\eta_{e l} \frac{\sqrt{1-p f_{C H P}^{2}}}{p f_{C H P}} \\
0 & 0 & 1 & \eta_{t h}
\end{array}\right]\left[\begin{array}{c}
P_{e p g}-P_{e p} \\
P_{e q g}-P_{e q} \\
P_{h g}-P_{h} \\
P_{f g}
\end{array}\right]} \\
& {\left[\begin{array}{c}
L_{e p}+L_{e p}^{H P} \\
L_{e q}+L_{e p}^{H P} \frac{\sqrt{1-p f_{H P}^{2}}}{p f_{H P}} \\
L_{h}-L_{e p}^{H P} * C O P
\end{array}\right]=\left[\begin{array}{lll}
1 & 0 & 0 \\
0 & 1 & 0 \\
0 & 0 & 1
\end{array}\right]\left[\begin{array}{c}
P_{e p g}-P_{e p} \\
P_{e q g}-P_{e q} \\
P_{h g}-P_{h}
\end{array}\right]} \\
& {\left[\begin{array}{c}
L_{e p} \\
L_{e q} \\
L_{h}
\end{array}\right]=\left[\begin{array}{cccc}
1 & 0 & 0 & 0 \\
0 & 1 & 0 & 0 \\
0 & 0 & 1 & Z_{h(h)}
\end{array}\right]\left[\begin{array}{c}
P_{e p g}-P_{e p} \\
P_{e q g}-P_{e q} \\
P_{h g}-P_{h} \\
\dot{E}_{h}
\end{array}\right]} \\
& {\left[\begin{array}{c}
L_{e p} \\
L_{e q} \\
L_{h}
\end{array}\right]=\left[\begin{array}{lll}
1 & 0 & 0 \\
0 & 1 & 0 \\
0 & 0 & 1
\end{array}\right]\left[\begin{array}{c}
P_{e p g}-P_{e p} \\
P_{e q g}-P_{e q} \\
P_{h g}-P_{h}
\end{array}\right]}
\end{aligned}
$$

where $\eta_{b}$ is the thermal efficiency of the gas boiler; $\eta_{e l}$ and $\eta_{t h}$ are the electrical and thermal efficiencies of the CHP plant, respectively; $p f_{C H P}$ is the power factor the CHP; COP is the coefficient of performance of the HP while $p f_{H P}$ is its power factor; The power factors of the HP and the CHP are taken to be positive if they are lagging and negative if they are leading.

In equation (5), the product of charging/discharging efficiency $\left(Z_{h(h)}\right)$ and the rate of change of stored heat in the thermal storage $\left(\dot{E}_{h}\right)$ gives the heat power going into the storage, i.e. $P_{h}^{\text {storage }}=Z_{h(h)} \dot{E}_{h}$. However, the charging and discharging performance of the thermal storage is variable. It highly depends on the temperature level of the water, its mass flow rate and the temperature difference with its surrounding. In addition, a surplus heat can only be stored if its temperature is higher than the temperature in the storage. Hence, the use of equation (5) with a constant charging and discharging efficiency could lead to unrealistic solutions. In order to overcome that challenge, the dynamics of the thermal storage is incorporated into the integrated load flow model. 


\subsubsection{Equations governing the dynamics of a stratified thermal storage}

Comparison of capacity (fully mixed) and stratified (with a layer that separates the cold and hot water) storage water tanks are presented in [45]. It is indicated that the use of stratified model gives better accuracy. Stratified thermal storage has also additional advantage over the fully mixed storage. As the layers of a stratified storage tank are kept at different temperature levels, it is possible to discharge the storage at higher temperatures whenever required. This is not possible in the fully mixed storage.

The water flow during charging and discharging process in a three-layer model of a stratified thermal storage tank is shown in Fig. 2. The middle layer serves as a buffer between the hot (top layer) and cold (bottom layer) water in the tank. Discharging takes place always from the top (hot) layer, as depicted in Fig. 2(b). During the charging process (see Fig. 2(a)), the incoming water temperature is first compared with the average temperature of each layer to determine where it should be stored. Accordingly, even if the incoming water is colder than the water in the top layer, it will still have a chance to be stored either in the middle or bottom layer of the storage. Such features are not possible using a fully mixed storage. The parameters that are used to model a three layer stratified thermal storage water tank are shown in Table 1.

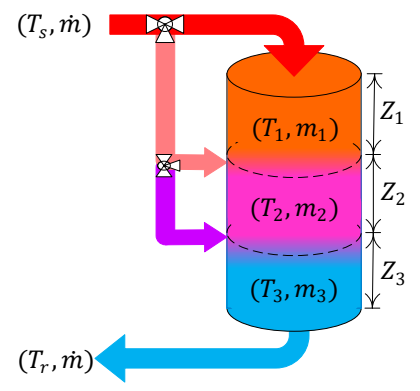

(a)

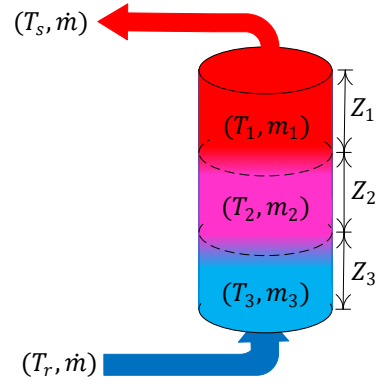

(b)

Fig. 2. Three layer stratified model of a thermal storage: (a) charging and (b) discharging.

Table 1: Parameters describing a stratified thermal storage model

\begin{tabular}{|c|c|}
\hline Symbols & Definition \\
\hline$K_{S}$ & Heat loss factor of the tank $\left(\mathrm{W} \cdot \mathrm{m}^{-2} \cdot \mathrm{K}^{-1}\right)$ \\
\hline$k_{w}$ & Thermal conductivity of water $\left(\mathrm{W} \cdot \mathrm{m}^{-1} \cdot \mathrm{K}^{-1}\right)$ \\
\hline$Z_{1}, Z_{2}$ and $Z_{3}$ & Heights of layer 1, layer 2 and layer $3(\mathrm{~m})$ \\
\hline $\mathrm{R}_{\text {storage }}$ & Radius (m) \\
\hline$A_{c}$ & Cross-section area of the storage $\left(\mathrm{m}^{2}\right)$ \\
\hline$A_{s 1}, A_{s 2}$ and $A_{s 3}$ & Lateral surface areas of layer 1, layer 2 and layer $3\left(\mathrm{~m}^{2}\right)$ \\
\hline$V_{\text {storage }}$ & Volume $\left(\mathrm{m}^{3}\right)$ \\
\hline$t$ & Time (s) \\
\hline$\Delta t$ & Time step (s) \\
\hline$T_{1(t-\Delta t)}, T_{2(t-\Delta t)}$ and $T_{3(t-\Delta t)}$ & Temperatures $(\mathrm{K})$ of water in layer 1 , layer 2 and layer 3 at $t-\Delta t$ \\
\hline$T_{1(t)}, T_{2(t)}$ and $T_{3(t)}$ & Temperatures $(\mathrm{K})$ of water in layer 1 , layer 2 and layer 3 at time $t$ \\
\hline$T_{a(t)}$ & Ambient (soil) temperature $(\mathrm{K})$ at time $t$ \\
\hline$m_{1}, m_{2}$ and $m_{3}$ & Mass $(\mathrm{kg})$ of water in layer 1, layer 2 and layer 3 \\
\hline$\dot{m}$ & Mass flow rate $(\mathrm{kg} / \mathrm{s})$ going into or leaving from the tank \\
\hline
\end{tabular}


Assuming an underground cylindrical water tank and a uniform soil temperature distribution around its surface, the optimal radius of a given storage volume $\left(V_{\text {storage }}\right)$ that minimizes the surface heat loss can be calculated using equation (7).

$$
R_{\text {storage }}=\sqrt[3]{V_{\text {storage }} / 2 \pi}
$$

The state of charge of the thermal storage can be expressed in terms of the water temperature in the three layers. During the charging process, the flow inside the storage is downward from top to bottom (Fig. 2(a)). The 'new' hot water inflows at the top layer (if $T_{S}$ is higher than $T_{1}$ ) while the 'older' cold water leaves from the bottom layer. The water flowing from layer 2 to layer 3, for example, is 'new' for layer 3, but old (from previous time) for layer 2. The governing equations are derived accordingly using the energy balance that considers the mixing of water at different temperatures and the losses to the surrounding. Coefficients and approximation models are adapted are adapted from a TRNSYS ${ }^{\circledR}[46]$ models. Equations (8) - (10) are used to update the temperatures at the three layers during charging phase.

$$
\begin{aligned}
& T_{3(t)}=\frac{1}{C_{p} m_{3}}\left\{C_{p} \dot{m} \Delta t\left(T_{2(t-\Delta t)}-T_{3(t-\Delta t)}\right)+\frac{A_{c} k_{w}\left(T_{2(t-\Delta t)}-T_{3(t-\Delta t)}\right) \Delta t}{0.5\left(Z_{2}+Z_{3}\right)}\right. \\
& \left.-A_{s 3} K_{s}\left(T_{3(t-\Delta t)}-T_{a(t)}\right) \Delta t+C_{p} m_{3} T_{3(t-\Delta t)}\right\} \\
& T_{2(t)}=\frac{1}{C_{p} m_{2}}\left\{C_{p} \dot{m} \Delta t\left(T_{1(t-\Delta t)}-T_{2(t-\Delta t)}\right)+\frac{A_{c} k_{w}\left(T_{1(t-\Delta t)}-T_{2(t-\Delta t)}\right) \Delta t}{0.5\left(Z_{1}+Z_{2}\right)}\right. \\
& -\frac{A_{c} k_{w}\left(T_{2(t-\Delta t)}-T_{3(t-\Delta t)}\right) \Delta t}{0.5\left(Z_{2}+Z_{3}\right)}-A_{s 2} K_{s}\left(T_{2(t-\Delta t)}-T_{a(t)}\right) \Delta t \\
& \left.+C_{p} m_{2} T_{2(t-\Delta t)}\right\} \\
& T_{1(t)}=\frac{1}{C_{p} m_{1}}\left\{C_{p} \dot{m} \Delta t\left(T_{s}-T_{1(t-\Delta t)}\right)-\frac{A_{c} k_{w}\left(T_{1(t-\Delta t)}-T_{2(t-\Delta t)}\right) \Delta t}{0.5\left(Z_{1}+Z_{2}\right)}-A_{s 1} K_{s}\left(T_{1(t-\Delta t)}\right.\right. \\
& \left.\left.-T_{a(t)}\right) \Delta t+C_{p} m_{1} T_{1(t-\Delta t)}\right\}
\end{aligned}
$$

For $T_{2}<T_{S} \leq T_{1}$ is the incoming flow bypasses layer 1 and flows directly into layer 2 . In that case, the $\dot{m}$ term in equation (10) is replaced by zero and the term $C_{p} \dot{m} \Delta t\left(T_{1(t-\Delta t)}-T_{2(t-\Delta t)}\right)$ in the equation (9) becomes $C_{p} \dot{m} \Delta t\left(T_{s}-T_{2(t-\Delta t)}\right)$. Similarly if $T_{3}<T_{s} \leq T_{2}$, the inflow will directly get into layer 3 . Hence, the $\dot{m}$ terms in equations (9) and (10) are replaced with zeros and the term $C_{p} \dot{m} \Delta t\left(T_{2(t-\Delta t)}-T_{3(t-\Delta t)}\right)$ in equation (8) is changed into $C_{p} \dot{m} \Delta t\left(T_{s}-T_{3(t-\Delta t)}\right)$. 
The temperatures at the three layers of the storage during the discharging phase are updated using equations (11)(13).

$$
\begin{aligned}
& T_{1(t)}=\frac{1}{C_{p} m_{1}}\left\{C_{p} \dot{m} \Delta t\left(T_{2(t-\Delta t)}-T_{1(t-\Delta t)}\right)-\frac{A_{c} k_{w}\left(T_{1(t-\Delta t)}-T_{2(t-\Delta t)}\right) \Delta t}{0.5\left(Z_{1}+Z_{2}\right)}-A_{s 1} K_{s}\left(T_{1(t-\Delta t)}\right.\right. \\
& \left.\left.-T_{a(t)}\right) \Delta t+C_{p} m_{1} T_{1(t-\Delta t)}\right\} \\
& T_{2(t)}=\frac{1}{C_{p} m_{2}}\left\{C_{p} \dot{m} \Delta t\left(T_{3(t-\Delta t)}-T_{2(t-\Delta t)}\right)+\frac{A_{c} k_{w}\left(T_{1(t-\Delta t)}-T_{2(t-\Delta t)}\right) \Delta t}{0.5\left(Z_{1}+Z_{2}\right)}\right. \\
& -\frac{A_{c} k\left(T_{2(t-\Delta t)}-T_{3(t-\Delta t)}\right) \Delta t}{0.5\left(Z_{2}+Z_{3}\right)}-A_{s 2} K_{s}\left(T_{2(t-\Delta t)}-T_{a(t)}\right) \Delta t \\
& \left.+C_{p} m_{2} T_{2(t-\Delta t)}\right\} \\
& T_{3(t)}=\frac{1}{C_{p} m_{3}}\left\{C_{p} \dot{m} \Delta t\left(T_{r}-T_{3(t-\Delta t)}\right)+\frac{A_{c} k_{w}\left(T_{2(t-\Delta t)}-T_{3(t-\Delta t)}\right) \Delta t}{0.5\left(Z_{2}+Z_{3}\right)}\right. \\
& \left.-A_{s 3} K_{s}\left(T_{3(t-\Delta t)}-T_{a(t)}\right) \Delta t+C_{p} m_{3} T_{3(t-\Delta t)}\right\}
\end{aligned}
$$

The integrated load flow simulation is conducted on an hourly basis (i.e. $\Delta t=1$ hour). Hence, the temperature of water leaving the storage is required not to vary during each hour. This constraint is handled by limiting the total hot (cold) water-mass leaving the storage in each hour to be less or equal to the water-mass in each layer. In addition, after following a natural stratified heat flow during each hour, the water in each layer is fully mixed at the end of each hour.

\subsubsection{Network power flow equations}

Each energy hub, as shown in Fig. 1, interact with the multicarrier distribution network so that any surplus is injected into the network and any shortage is compensated by importing from the network. The power injected into the network is further expressed in terms of distribution network's physical and operating parameters that govern the power flows in the respective distribution networks. In that way, a given energy hub interacts with all other hubs and allows bidirectional power flows.

\subsubsection{Electricity flow model}

The electricity flow model defines the pu active and reactive power injections from a given bus $k$ as a function of all nodal voltages and line parameters, as shown in equations (14) and (15) respectively [47].

$$
P_{e p(k)}=\sum_{j=1}^{N}\left|V_{k}\right|\left|V_{j}\right|\left(G_{k j} \cos \theta_{k j}+B_{k j} \sin \theta_{k j}\right)
$$




$$
P_{e q(k)}=\sum_{j=1}^{N}\left|V_{k}\right|\left|V_{j}\right|\left(G_{k j} \sin \theta_{k j}-B_{k j} \cos \theta_{k j}\right)
$$

where $\theta_{k j}$ is the voltage angle difference between bus $k$ and bus $j ; G_{k j}+j B_{k j}=Y_{k j}$ is an element of the network admittance matrix, $\left|V_{k}\right|$ is the voltage magnitude at bus $k$ and $N$ is the total number of buses.

\subsubsection{Thermo-hydraulic model}

The thermo-hydraulic model describes the conservation of mass and energy in the heating network. The hydraulic model is expressed using pipe equations. This model consists of nodal mass conservation and pipe pressure drop equations, which are given by equations (16) and (17), respectively [33].

$$
\begin{aligned}
& \left.\left.\sum \text { (all mass flows into the node }\right)=\sum \text { (all mass flows leaving the node }\right) \\
& H_{j}-H_{i}=(\text { sign }) k_{i j}\left|\dot{m}_{j i}\right|^{2}=k_{i j} \dot{m}_{j i}\left|\dot{m}_{j i}\right|
\end{aligned}
$$

where $H_{j}$ and $H_{i}$ are the hydraulic heads at nodes $j$ and $i$ respectively while $\dot{m}_{j i}$ is the mass flow rate flowing from node $j$ to node $i ; k_{i j}$ is the pressure resistance coefficient of the corresponding pipe.

The thermal model, on the other hand, is defined by nodal heat power injections, nodal conservation of energy and temperature drop across each pipe. The nodal heat power injected from hub $i$ is the amount of heat supplied from a given hub $i$ into the network, which is given by equation (18).

$$
P_{h(i)}=C_{p} \dot{m}_{(i)}\left(T_{S(i)}-T_{r(i)}\right)
$$

where $\dot{m}_{(i)}$ is the mass flow rate of water injected from hub $i$ into the network (on the supply side) while $T_{s(i)}$ and $T_{r(i)}$ are its temperatures on the supply and return sides, respectively. $C_{p}$ is the specific heat capacity of water.

The conservation of energy at each node $j$ (assuming complete mixing of water flows) is given by equation (19).

$$
\sum_{\begin{array}{c}
p \in \text { pipe flows } \\
\text { going into node } j
\end{array}} T_{j(p)} \dot{m}_{p}=T_{j(\text { out })} \sum_{\begin{array}{c}
p \in \text { pipe flows } \\
\text { leaving node } j
\end{array}} \dot{m}_{p}
$$

where $T_{j(p)}$ is the temperature of water in pipe $p$ going into node $j$ while $T_{j(\text { out })}$ is the temperature of outgoing flows from node $j$. The $\dot{m}_{p}$ term stands for the flow rate in pipe $p$.

The inlet and outlet temperatures of water for each pipe $p$ are related using equation (20). 


$$
T_{j(p)}=T_{a}+\left(T_{i(p)}-T_{a}\right) \exp \left(-\frac{U 2 \pi R_{o} L}{C_{p} \dot{m}_{p(i j)}}\right)
$$

where $T_{i(p)}$ and $T_{j(p)}$ are the inlet and outlet water temperatures of pipe $p$ connecting nodes $i$ and $j$, respectively, while $T_{a}$ is the soil temperature at the surface of the pipe. $\dot{m}_{p(i j)}$ is the flow rate in the pipe in the direction of $i$ to $j . U$ is the overall heat transfer coefficient between the water in the pipe and the surrounding soil. $R_{o}$ is the outer radius of the pipe jacket and $L$ is the length of the pipe.

All of the thermo-hydraulic quantities are expressed in a common pu system so that they can be solved simultaneously with the electricity flow and coupling equations. The derivation of the common pu system can be referred from [40].

\subsection{Population-based optimization}

The objective of the optimization is to lower the operating cost of the overall system by optimally scheduling the charging and discharging of the thermal storage in the presence of intermittent renewable energy source and variable electricity price signal together with the full consideration of the electricity and heat distribution networks' parameters. As the problem is highly nonlinear and nonconvex, a metaheuristic optimization algorithm is proposed in this paper.

\subsubsection{Objective function}

The objective function of the integrated optimal power flow is minimization of the daily operating cost of the MES, which is defined using equation (21). The operating cost is the sum of all costs of local generations and imports of heat, electricity and fuel (equation (22)).

$$
\begin{aligned}
& \mathcal{F}=\min \left\{\sum_{\text {hour }=1}^{24}(\text { Operating cost })_{\text {hour }}\right\} \\
& \text { Operating cost }=\sum_{\text {hubs }} C_{P h g}+\sum_{\text {hubs }} C_{P e l g}+\sum_{\text {hubs }} C_{P f g} \pm C_{P h(1)} \pm C_{P e l(1)}
\end{aligned}
$$

where $C_{P h g}$ and $C_{P e l g}$ are the costs of locally generated heat and electricity, respectively, while $C_{P f g}$ refers to the fuel consumed by the coupling technologies at different hubs. The terms, $\pm C_{P h(1)}$ and $\pm C_{P e l(1)}$ refers to the cost of heat and electricity imported (positive) or exported (negative) at the slack hub, respectively.

In literature, the total electricity consumption of the circulation pumps is very small when compared to the total electrical demand in the system [17]. Hence, their impact on the operational parameters of the electricity network 
can be neglected. However, in a thermo-economic optimisation, when supply temperatures are reduced to minimize the heat distribution loss, the mass flow rate circulating in the network rises. Consequently, the increase in the electricity consumption of the circulation pumps may cost-wise compete with the decrease in the heat loss. Hence, the pumping cost is considered as part of the imported electricity at the slack hub.

The circulation pumps serve two purposes. The first is to overcome the frictional and local pressure losses in the heating network while the second is to guarantee the minimum pressure difference required between the supply and the return pipes on the primary side of a remote consumer substation. The corresponding electricity consumptions are calculated using equation (23) (first and second terms on the right hand side, respectively).

$$
P_{e l(\text { pumping })}=\left(1+C_{\text {loc }}\right) * \sum_{p \in \text { all pipes }} \frac{g *\left|\Delta H_{p} * \dot{m}_{p}\right|}{\eta}+\sum_{c \in \text { consumers }}\left(\frac{g * \Delta H_{c}}{\eta}\left|\dot{m}_{c}\right|\right)
$$

where $P_{e l(\text { pumping }}$ is the active electric power consumed by circulation pumps; $g$ is the gravitational acceleration; $\Delta H_{p}$ is the frictional head loss on a pipe $p$ (assuming straight pipe); $\left|\dot{m}_{p}\right|$ is the magnitude of the mass flowrate in the pipe; $\eta$ is efficiency of the circulation pump (it is assumed to be $80 \%$ ); $C_{l o c}$ is a fraction to take the local pressure losses due to valves and junctions into account; $\Delta H_{c}$ is the hydraulic head difference at the consumer substation in meter while $\left|\dot{m}_{c}\right|$ is the magnitude of mass flow rate on the primary side of the substation. In this paper, the values of $C_{l o c}$ and $\Delta H_{c}$ are assumed to be 0.3 and $5.1 \mathrm{~m}(\approx 50 \mathrm{kPa})$, respectively [48].

\subsubsection{Equality and inequality constraints}

The integrated load flow model that governs the heat and electricity distribution networks is used as a main equality constraint in the optimisation. Hence, equations (1) - (20) serve as equality constraints for the optimization problem. In addition, the following inequality constraints are considered: the voltage limit at each bus (equation (24)), the limit on line current (equation (25)), maximum allowed mass flow in each pipe (equation (26)), the limit on the supply temperatures of heat-source hubs (equation (27)) and the limit on the return temperatures of heat consuming hubs (equation (28)).

$$
\begin{aligned}
& V_{\min } \leq\left|V_{k}\right| \leq V_{\max } \\
& 0 \leq\left|I_{i j(r m s)}\right| \leq I_{\max } \\
& 0 \leq\left|\dot{m}_{i j}\right| \leq \dot{m}_{\max } \\
& T_{s(\min )} \leq T_{s(k)} \leq T_{s(\max )}, \text { for net-heat-source hubs }
\end{aligned}
$$




$$
T_{r(\min )} \leq T_{r(k)} \leq T_{r(\max )} \text {, for net-heat-consuming hubs }
$$

\subsubsection{Optimization algorithm}

Thermal storages can be operated using rule-based strategies [18]. The rules are usually defined based on the conditions at a given instant of time. As a result, they are not able to capture any forthcoming opportunity. The opportunity can be due to variable tariffs and/or surplus production from renewables. In order to exploit such opportunities, the rules themselves need to be optimized considering a given time horizon. These kinds of problems are usually tackled using model predictive control (MPC) algorithms [49]. The time horizon should be short enough to reduce the computational cost, but also long enough to capture all possible opportunities.

Hot water thermal storage tanks are usually designed for shaving the heat demand and capturing the cheap electricity prices that occur during the day [50]. In that regard, a time horizon of 24 hours is considered to demonstrate how the synergy of heat and electricity distribution networks can be exploited. Hence, a populationbased optimisation technique is implemented in the form of MPC algorithm with a fixed window. Optimisation over a longer period with the consideration of uncertainties in generation and demand forecast can be implemented by easily adapting the proposed method with a sliding window, which is beyond the scope of this paper.

The proposed population-based optimisation algorithm is illustrated in Fig. 3. It start by taking input data that describes the topology and parameters of both the heating and electricity distribution networks. Based on the input data, the integrated load flow problem is formulated and the decision variables are identified. This is followed by a structure definition of the population-based optimisation algorithm. Each of the $N$ candidates in the population contain the hourly decision variables cascaded over the 24-hours horizon. To evaluate the fitness of each candidate, the values of the decision variables for each hour are extracted. Then, the integrated load flow model (discussed in Section 3.1) is simulated on an hourly-basis. This includes simulation of the thermal storage at each hour. Hourly operating costs are then calculated. Penalty factors are taken into account for any violation of the constraints. The sum of the operating cost over the 24 hours gives the fitness of the candidate. Once all the candidates have gone through such similar steps, the global best candidate and the global best fitness value are updated by comparing the best fitness of all the candidates with the previous global best fitness value. Then the candidates update their position in the search space using their personal best and global best positions as input. That is followed by fitness evaluation and then updating the global best fitness value. The iteration continues until the optimality condition is satisfied or the maximum iteration is reached. In this paper a particle swarm optimization (PSO) technique, which was introduced in [51], is used to implement the proposed population-based algorithm. 


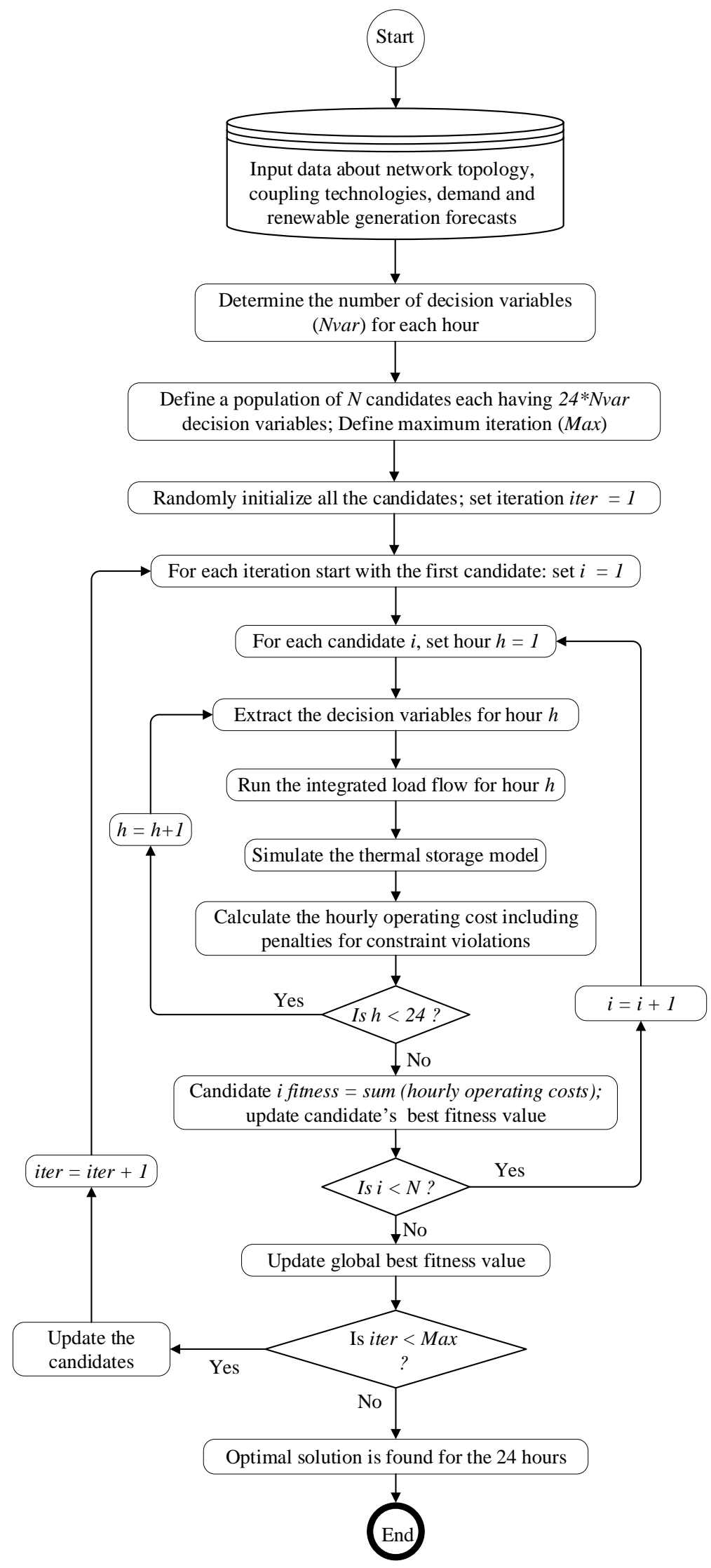

Fig. 3. A population-based operational optimisation of coupled electricity and heat distribution networks with a thermal storage. 


\section{Case study}

A hypothetical energy system consisting of 13-hubs, as shown in Fig. 4, is considered to test the proposed models and methods. A thermal storage is installed at hub 1, a HP at hub 2, a wind power plant at hub 5, a gas boiler at hub 6 and a CHP at hub 10. Hub 1 is also used as a slack hub where interaction with the electricity grid takes place.

The analysis is repeated by removing the thermal storage.

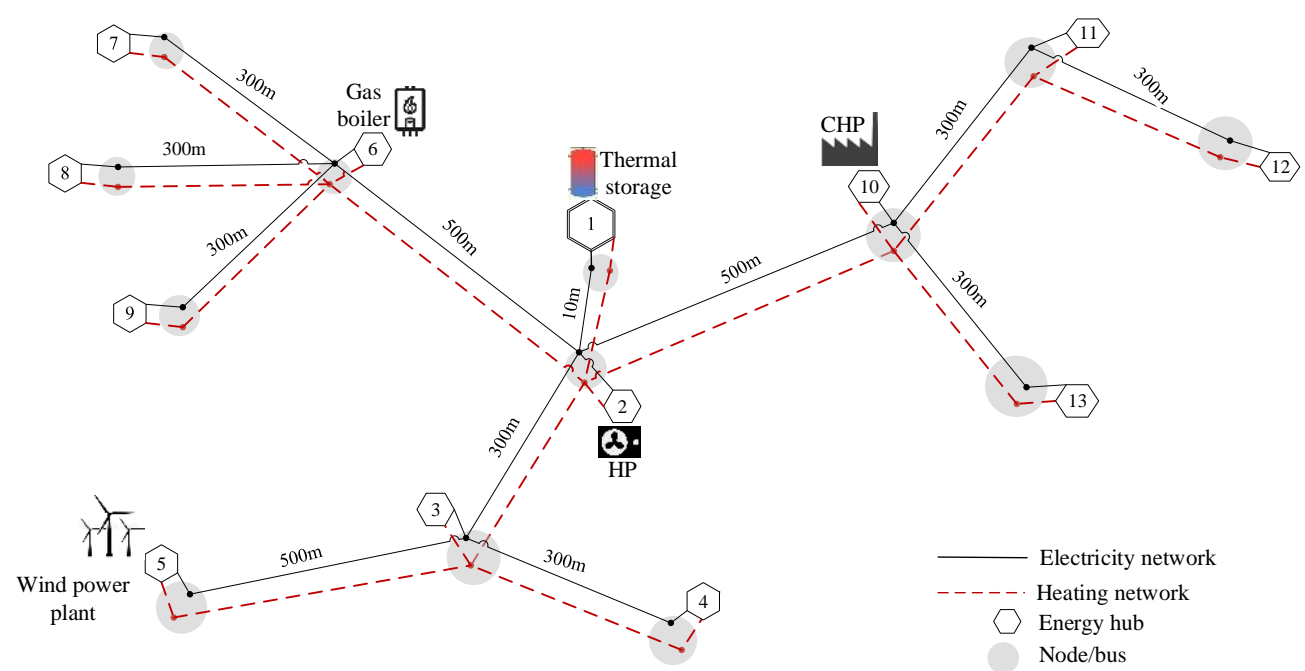

Fig. 4. Layout of a 13-hubs combined heat and electricity distribution network.

\subsection{Input parameters and assumptions}

Although the selected case study has a hypothetical topology, realistic input data and parameters are used wherever they are available. The rest are assumed within the range of typical values.

- All the heating network pipes are assumed to be DN-50 type with standard insulation, data taken from [52]. To avoid noise and wearing in the pipes, the water speed inside the pipes should not exceed $3.5 \mathrm{~m} / \mathrm{s}$ [48]. This implies an upper bound flowrate limit of $7.85 \mathrm{~kg} / \mathrm{s}$ for all DN-50 pipes. The water in the heating network pipes is assumed to be incompressible with constant density $\left(982.6 \mathrm{~kg} / \mathrm{m}^{3}\right)$, specific heat capacity $(4.185 \mathrm{~kJ} / \mathrm{kgK})$, viscosity $\left(485 \mu \mathrm{NS} / \mathrm{m}^{2}\right)$ and conductivity $(0.6516 \mathrm{~W} / \mathrm{mk})$.

- The electricity network is a balanced $4.16 \mathrm{kV}$ three-phase system. All transmission lines are ACSR Waxwing type with resistance, reactance, susceptance and ampacity values of $0.262 \Omega / \mathrm{km}, 0.386 \Omega / \mathrm{km}$, $4.31 \mu \mathrm{S} / \mathrm{km}$ and $480 \mathrm{~A}$, respectively [53]. The allowed nodal voltage range is between 0.95 and 1.05 per unit. 
- The CHP plant has a gas intake capacity of $538 \mathrm{~kW}$, and its thermal and electrical efficiencies are $49 \%$ and $37 \%$, respectively [54]. It runs at unity power factor.

- The gas boiler can take a maximum of $300 \mathrm{~kW}$ of gas with a thermal efficiency of $90 \%$.

- $\quad$ The HP is rated at $200 \mathrm{~kW}_{\mathrm{e}}$ with a 0.9 lagging power factor. Its COP is taken to be 4.0.

- A wind power plant of type Winflow (500 kW) running at unity power factor is considered. Its output is forecasted using HOMER [19]. The operating cost of the wind power plant is neglected.

- The price of gas is $0.064 € / \mathrm{kWh}$. Two price levels are considered for grid electricity (for active power): $0.15 € / \mathrm{kWh}$ during the cheap hours $(23: 00-06: 00)$ and $0.2 € / \mathrm{kWh}$ during the expensive hours $(07: 00-$ 22:00), respectively. These prices are rough approximations of the French market for 2020.

- A supply temperature ranges of $65-95^{\circ} \mathrm{C}$ is assumed for all hubs injecting heat into the network. In [29], it has been shown that the lowest possible value of the return temperature at heat consuming hubs is always selected in the optimisation. Hence, a fixed return temperature of $35^{\circ} \mathrm{C}$ is assumed at all heat consuming hubs, except the slack hub where the storage is installed. The temperature at any place on the heating network is not allowed to fall below $15^{\circ} \mathrm{C}$.

- A $40 \mathrm{~m}^{3}$ thermal storage is considered with $1.1189 \mathrm{~W} / \mathrm{m}^{2} \mathrm{~K}$ loss factor [46]. Its initial temperature is assumed to be uniform and equal to $35^{\circ} \mathrm{C}$.

- In order to investigate the full capacity of the thermal storage, the heating network is assumed to be in islanded mode. As a result, there are no import and export possibilities in the heating network. The electrical network, on the other hand, can import from the external grid. But, the incentives for feeding in excess production is assumed to be zero.

\subsection{Load and wind generation profiles}

All, but hubs 1 and 5, have both electricity and heat demands. Fig. 5 shows the hourly heat and active electric power demands at different hubs for a typical winter day in February. The heat demand profiles are taken from measurement in the Nantes DHN. Then, the electricity load profiles are generated using a linear correlation between the heat and electricity demands of residential buildings in a similar weather, which are available online 
at Open Energy Information database [55]. All connected electrical loads are assumed to have a 0.95 lagging power factor.

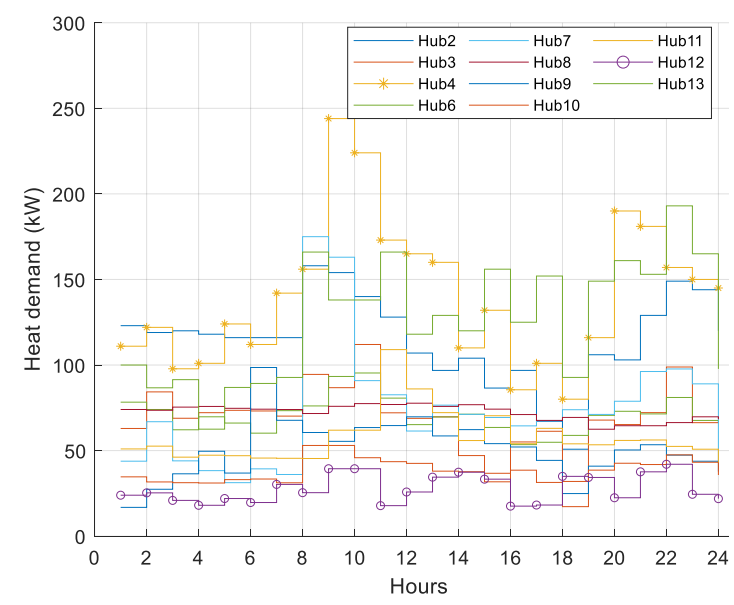

(a)

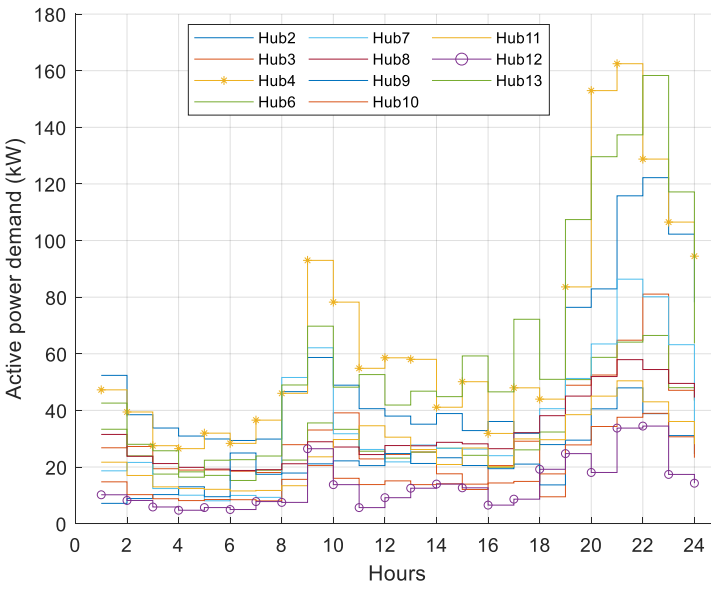

(b)

Fig. 5. Demand profiles at different hubs: (a) heat power and (b) active electric power.

The soil temperature (data taken from [56]), the total demand and the wind generation for the given day are plotted in Fig. 6 together with the price signal of grid electricity. It can be observed from Fig. 6 that the peak heat and electricity demands occur at different times. The heat demand peaks $(1164.7 \mathrm{~kW})$ at 9:00 while the active and reactive power demands reach their peaks $(858.55 \mathrm{~kW}$ and $281.6 \mathrm{kvar}$, respectively) at 21:00. The daily residential demands of heat, active and reactive powers are 20.228 MWh, 9.335 MWh and 3.062 Mvarh, respectively. The electricity demands, however, do not take the consumption of the HP into account. The additional electricity demands due to the operation of the HP are discussed in Section 5.2.

Fig. 6 also shows that the active power generated from the wind generation, with zero cost, is higher than the active power demand during the hours 11:00 - 17:00. The surplus amounts 1.176 MWh, which accounts for $20.37 \%$ of the total production $(5.772 \mathrm{MWh})$ of the wind power plant. In addition, during the off-peak hours, the grid electricity price is relatively cheaper, as shown in Fig. 6(c). The integrated optimisation is conducted to exploit such opportunities by finding out the synergy of the heating and the electricity energy systems, which could be otherwise impossible. 

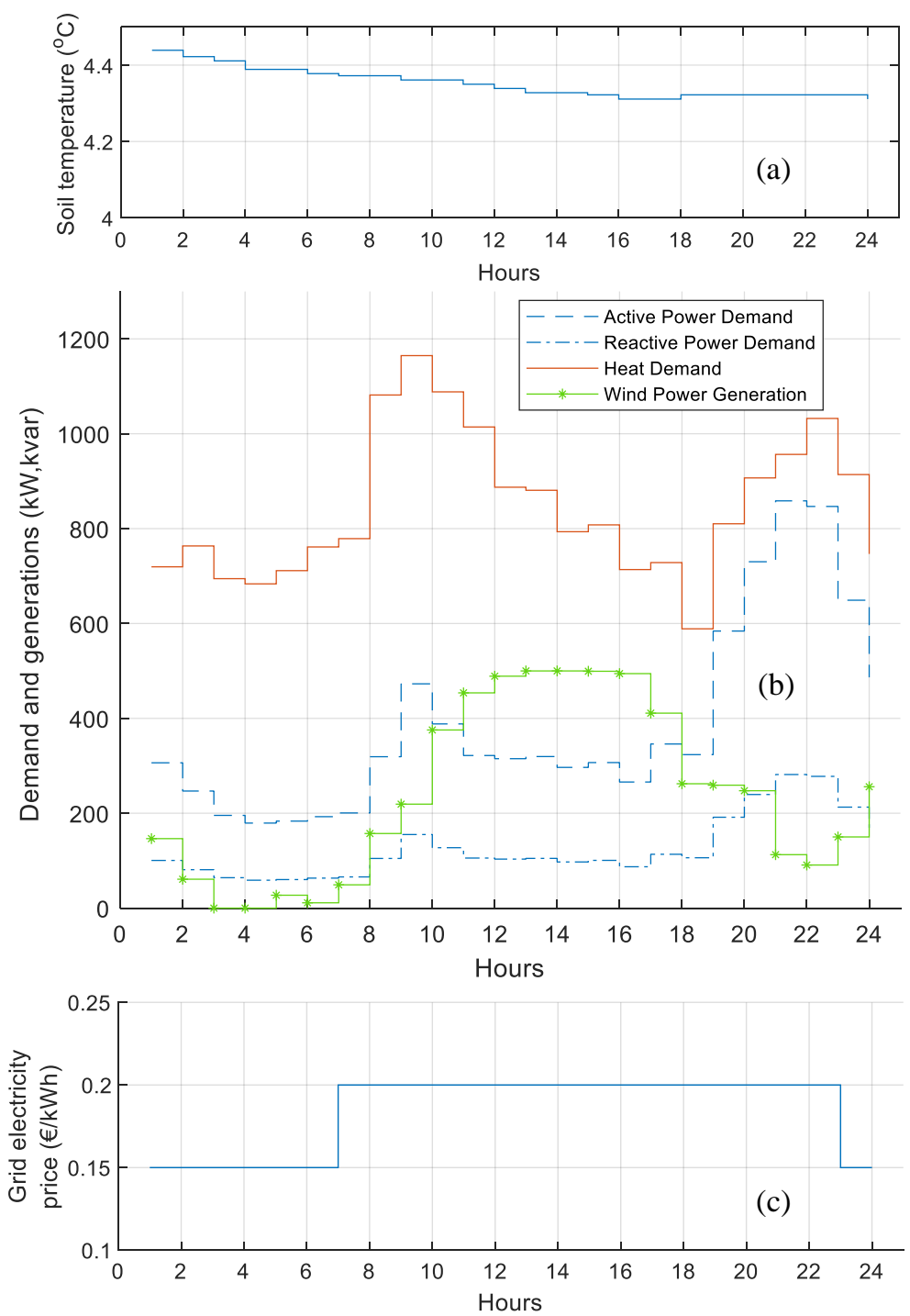

Fig. 6. Profiles of (a) soil temperature, (b) total active, reactive and heat power demands, and wind turbine power generation and (c) price of electricity from the grid for a typical winter day.

\subsection{Scenarios and decision variables}

In order to quantify the synergy obtained from thermal storage integration, two scenarios are defined as follows:

I. In the first scenario, the system is run without a thermal storage.

II. The thermal storage is considered in the second scenario.

The values of six main decision variables for each hour are determined directly by the optimisation algorithm. Three of them are for the dispatches of the CHP, the HP and the gas boiler while the other three are for the supply temperatures at the corresponding hubs. In addition, there are four more decision variables that are evaluated indirectly from the other decision variables using the integrated load flow model. Two of them are the supply 
temperature and the heat power going to/from the storage while the other two are the active and reactive power imports at the slack hub.

\section{$5 \quad$ Results and discussions}

Selected results are discussed in this section. First the energy balance and selected operating parameters of the DHN are discussed, followed by a discussion on the energy balance and selected operating parameters of the electricity distribution network. Finally, a summary of results at the system level is presented.

\subsection{Energy balance and operating parameters of the heating network}

The heat generated from the CHP $\left(P_{h}^{C H P}\right)$, the $\mathrm{HP}\left(P_{h}^{H P}\right)$ and the gas boiler $\left(P_{h}^{\text {Boiler }}\right)$ in the two scenarios are shown in Fig. 7. The CHP is running at full capacity during all hours except between 11:00 - 18:00 in Scenario I and between 11:00 -17:00 in Scenario II. The hours 11:00 - 17:00 correspond to the interval when the electricity generation from the wind turbine is higher than the active electricity demand (see Excess $P_{\text {epg (wind) }}$ in Fig. 7) while hour 18:00 is when the heat demand is at it its lowest value.

For the system without a thermal storage, as shown in Fig. 7(a), the CHP and the HP are used most of the time (between hours 1:00 - 7:00, 17:00 - 21:00, at 23:00 and at 24:00). Combinations of the gas boiler, the HP and the CHP are used between 8:00 - 13:00, at 15:00 and at 22:00. At hour 16:00, the HP is used alone while the HP and the gas boiler are used together at hour 14:00.

The terms $P_{h}^{\text {stored }}$ and $P_{h}^{\text {discharged }}$ in Fig. 7(b) refer to the charging and discharging heat power flows to and from the storage, respectively. The figure also shows that the gas boiler is completely avoided, and the peak-hour heat demands are effectively shifted to the hours at which there is cheap electricity. It also shows that there is higher discharge from the thermal storage at hour 9:00. This hour corresponds to the peak heat demand, expensive grid electricity and no surplus from the wind turbine. Hence, the CHP generates heat and electricity at its full capacity. Part of the electricity is used to supply the electricity demand and the remaining is used to run the HP. Any deficit is then covered by discharging the thermal storage.

The HP runs at/near to its full capacity during hours 14:00 and 16:00 in Scenario I (Fig. 7 (a)). This is due to the higher surplus of electricity from the wind turbine at these hours (200.4 kW and $225.6 \mathrm{~kW}$, respectively). As a result, the HP runs at its maximum capacity consuming $200 \mathrm{~kW}$ of the excess production. The left overs, $0.4 \mathrm{~kW}$ and $25.6 \mathrm{~kW}$ of active powers, are used by the circulation pumps (which require $1.9 \mathrm{~kW}$ and $1.04 \mathrm{~kW}$ respectively). 
Accordingly, there will be $24.56 \mathrm{~kW}$ of net surplus electricity at hour 16:00. The heat produced from the HP at hour 16:00 is sufficient to cover the demand and the loss. However, additional heat is required at 14:00 to compensate the distribution loss (nearly $80 \mathrm{~kW}$ as shown in Fig. 8). As the electricity demand is already met, the gas boiler is opted over the CHP for its higher thermal efficiency to cover the heat deficit. This implies that the economic dispatch of the technologies at a given hour depends on the heat and electricity demands, the price of the different energy carriers and their availability.

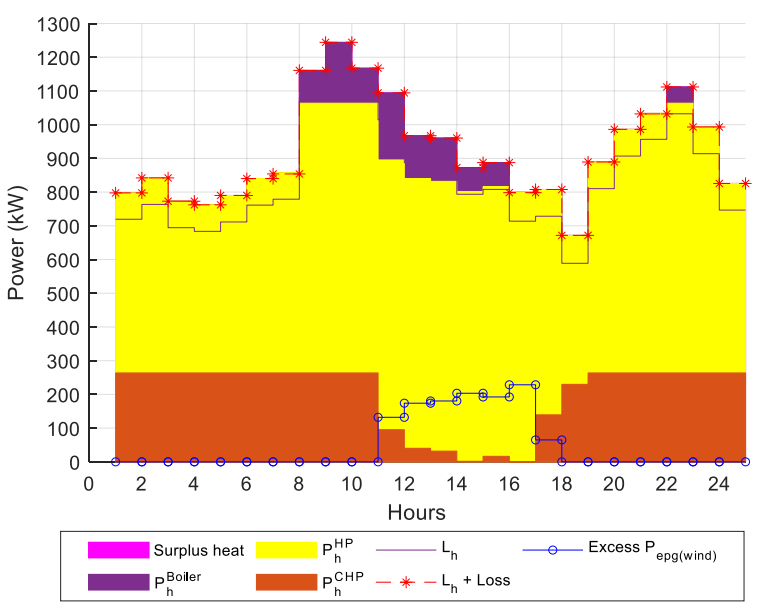

(a)

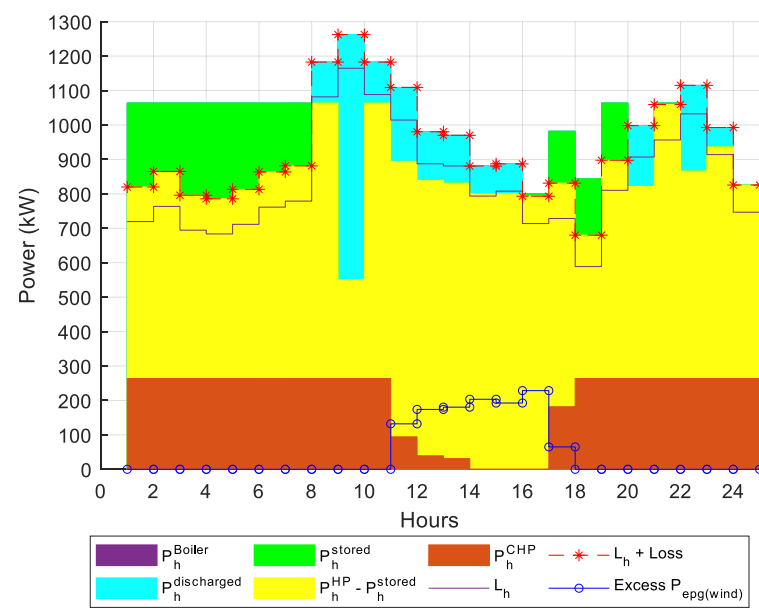

(b)

Fig. 7. Heat generation and consumption: (a) without a thermal storage (b) with a thermal storage.

The comparison of the two scenarios in terms of heat loss is illustrated in Fig. 8. The figure shows that integration of a thermal storage resulted in an increase of heat loss which is in agreement with [13]. This can be further investigated by looking the temperature profiles of the thermal storage and the heating network.

The charging and discharging evolution of the thermal storage is illustrated in Fig. 9. The left axis shows the stored energy (in blue) as a measure of the state of charge while the right axis shows the temperatures at different layers (in red). The stored energy is calculated by taking $35^{\circ} \mathrm{C}$ as a zero reference. It can also be observed that the thermal storage was fully discharged twice in the 24 hours. The negative values of stored energy, at some hours after the storage is fully discharged, are caused by the temperature drops below $35^{\circ} \mathrm{C}$ due to the heat loss to the surrounding soil. On the other hand, the temperature at the top layer is always below the maximum of $95{ }^{\circ} \mathrm{C}$ (maximum temperature in the system). This shows that the storage did not yet reach its full capacity.

The temperature profiles of selected hubs are shown in Fig. 10. Hubs 1, 2, 6 and 10 correspond to the location of the thermal storage, the HP, the gas boiler and the CHP, respectively. It can be seen from Fig. 10(a) that the supply temperatures are close to $65{ }^{\circ} \mathrm{C}$ most of the time. For some hours, however, the supply temperatures of hubs 6 and 
10 drop slightly below $65^{\circ} \mathrm{C}$. At those hours, the hubs are acting as a net-heat consumer. Hence, their return temperatures are fixed at $35{ }^{\circ} \mathrm{C}$, as shown in Fig. 10(a), and their supply temperatures are determined from the network.

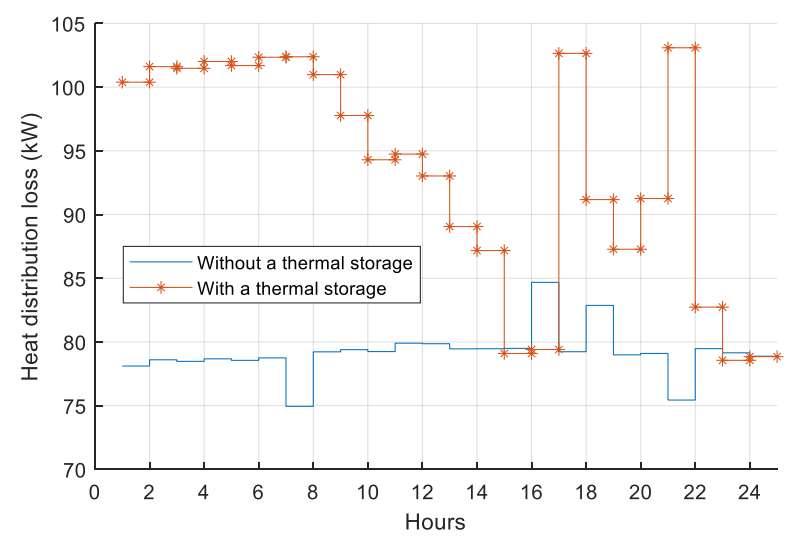

Fig. 8. Heat loss comparison between the two scenarios.

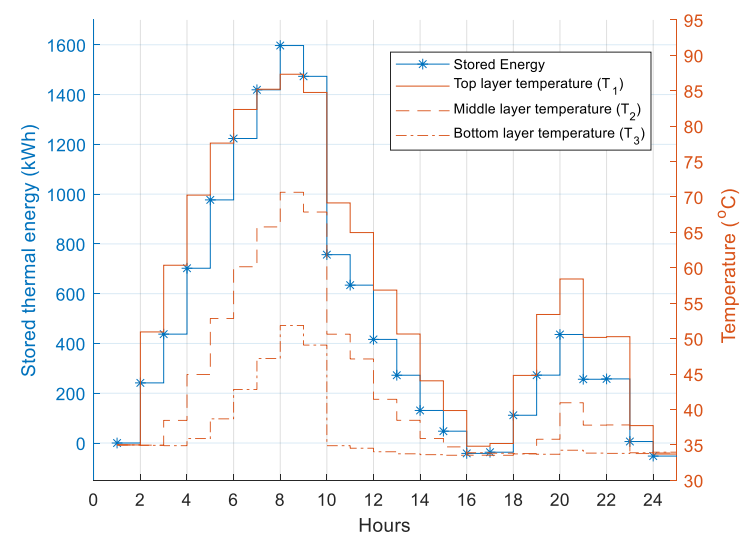

Fig. 9. The state of charge and temperature profiles at different layers of the thermal storage.

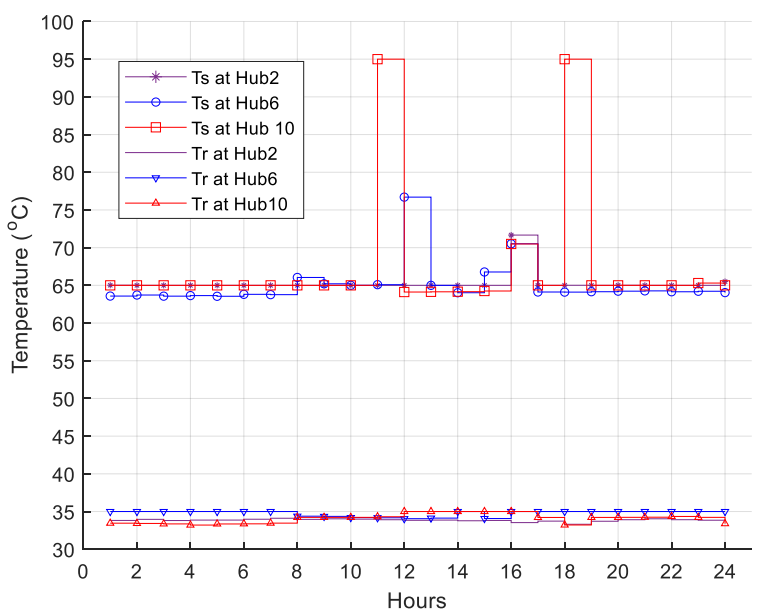

(a)

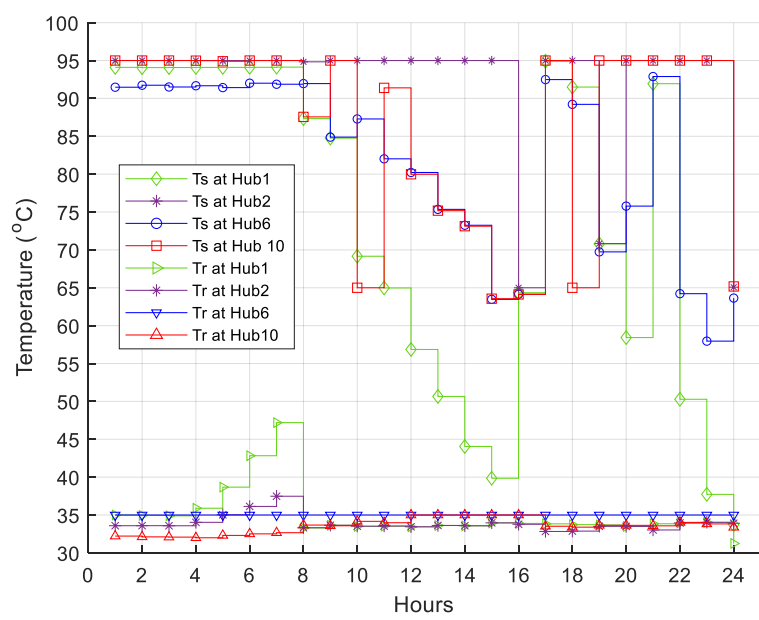

(b)

Fig. 10. Supply and return temperature profiles at selected hubs: (a) without a thermal storage and (b) with a thermal storage. 
Fig. 10(b), on the other hand, shows that the source temperatures are near to $95{ }^{\circ} \mathrm{C}$ while the storage is charging (for example between 1:00-7:00). There is also a corresponding rise in the return temperature for hubs 1 and 2 above $35{ }^{\circ} \mathrm{C}$.

The results from Fig. 9 and Fig. 10 imply that the optimal supply temperatures of the heat sources are relatively higher in a DHN with a thermal storage. That higher temperature profile enables the storage to save more heat and discharge at higher temperature. The higher the temperature, on the other hand, means the higher the distribution loss.

The pipe flows for the two scenarios are shown in Fig. 11. All the pipe flows are below the acceptable limit of $7.85 \mathrm{~kg} / \mathrm{s}$. It can be seen that the flowrate in Pipe 3-5 is always zero in both scenarios. It is because of zero heat demand connected at Hub5. The flow in Pipe 2-10 changes between negative and positive in both scenarios, though at different magnitudes. The flow arte in Pipe 1-2 is almost zero all time in Scenario I indicating negligible heat flow to the slack hub (see Fig. 11(a)). However, there is high flow rate (oscillating between negative and positive values) in the same pipe for scenario II corresponding to the charging and discharging of the thermal storage.

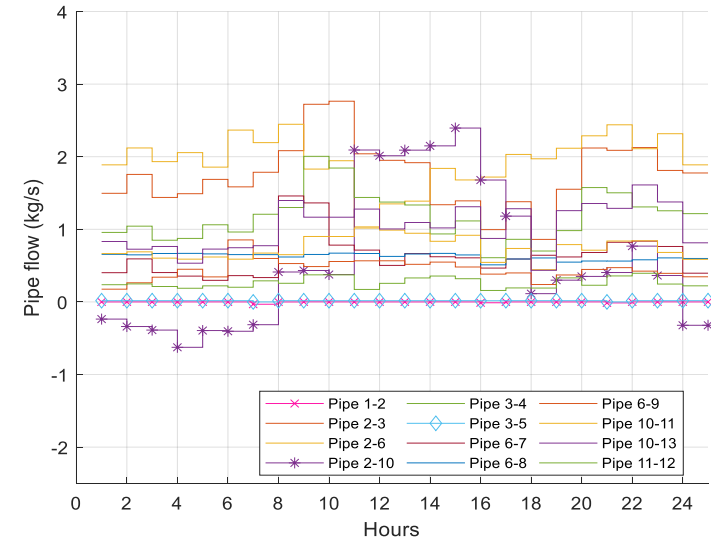

(a)

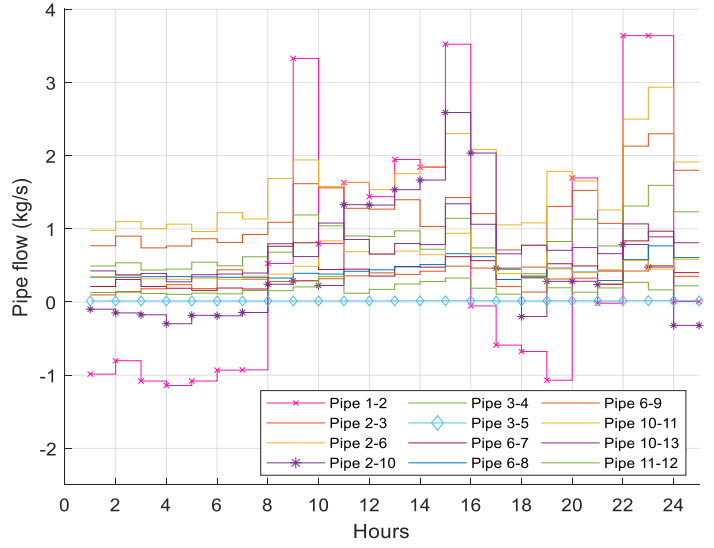

(b)

Fig. 11. Pipe flows after thermo-economic optimisation: (a) without a thermal storage and (b) with a thermal storage.

\subsection{Energy balance and operating parameters of the electricity network}

The active and reactive power production and consumption for the two scenarios are shown in Fig. 12 and Fig. 13. The terms $P_{e p g(\text { wind })}$ and $P_{e p}^{C H P}$ refer to the active electric power generated by the wind turbine and the CHP, while $L_{e p}^{H P}$ and $L_{e q}^{H P}$ represent the active and reactive power consumptions of the HP, respectively. As discussed in the previous section, the surplus of electricity at hour 16:00 is because of the limit in the capacity of the HP. Comparing Fig. 12(a) and Fig. 12(b), it can be seen that the system with a thermal storage has imported more active electricity 
from the grid during the cheap hours 1:00 - 7:00. The excess electricity is converted into heat by the HP and is used to charge the thermal storage (see Fig. 7(b)). As the HP is running at lagging power factor, more reactive power is imported in the corresponding hours as shown in Fig. 13(b).

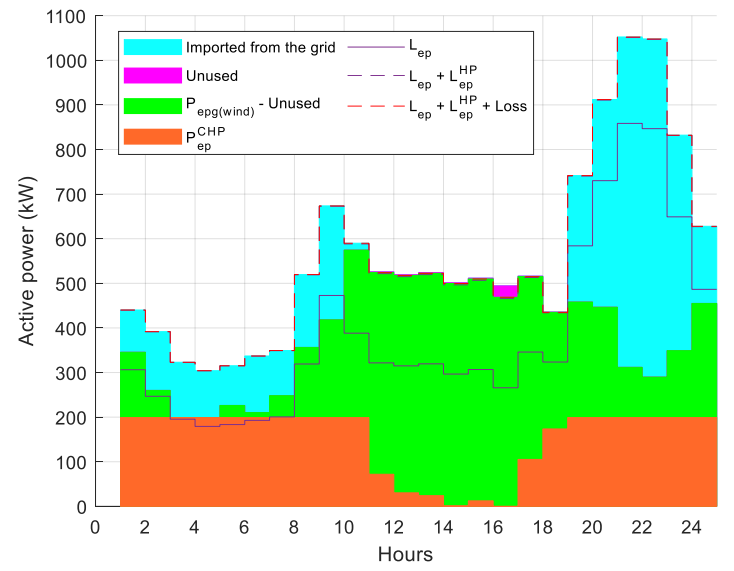

(a)

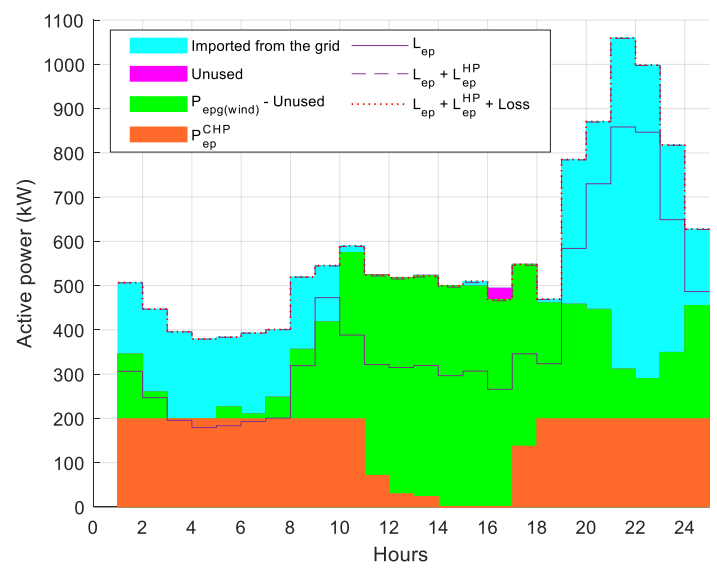

(b)

Fig. 12. Active electricity generation and consumption: (a) without a thermal storage and (b) with a thermal storage.

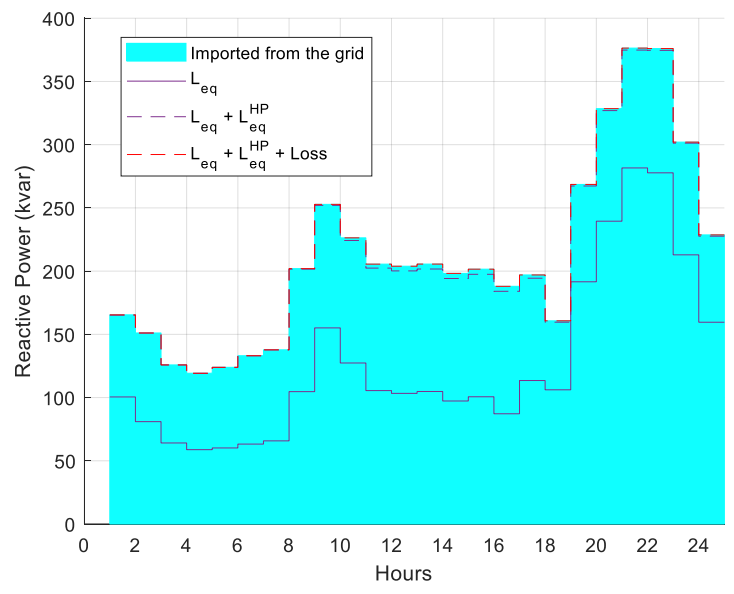

(a)

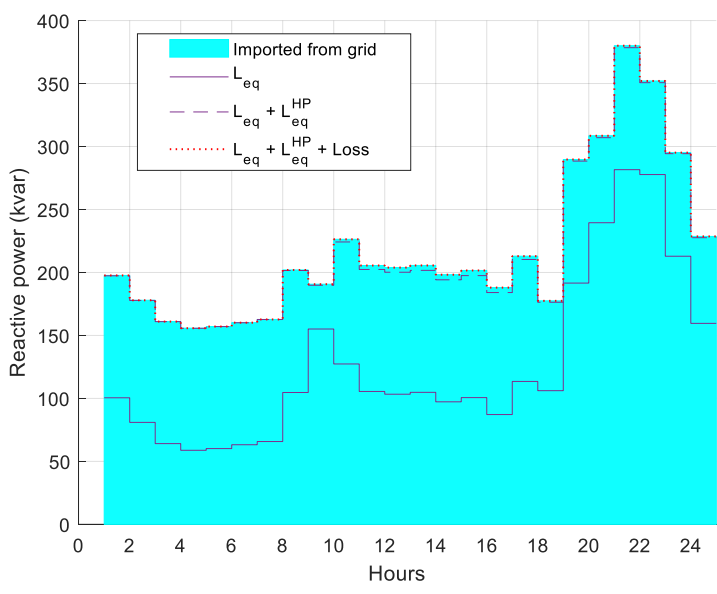

(b)

Fig. 13. Reactive electricity generation and consumption: (a) without a thermal storage and (b) with a thermal storage.

Fig. 14 shows the active and reactive power losses, which are very low in both scenarios relative to the total demand. Having short transmission lines at a relatively high voltage level is the main contributing factor for such low distribution losses. Both the active and reactive power losses are relatively higher during the hours at which the CHP (as a distributed generation) is turned off.

The voltage profiles are also very close to unity in both scenarios, as shown in Fig. 15. Hub 1 is a reference hub and its voltage is fixed at $1 \mathrm{pu}$. Hub 5 is where the wind power plant is installed. Hence, its voltage magnitude follows the output pattern of the wind generation. As a result, it is the same in both scenarios. Slight differences, 
however, can be observed for hub 10 at hours 17:00 and 18:00 during which the CHPs in the two scenarios are dispatched at different levels (see Fig. 12).

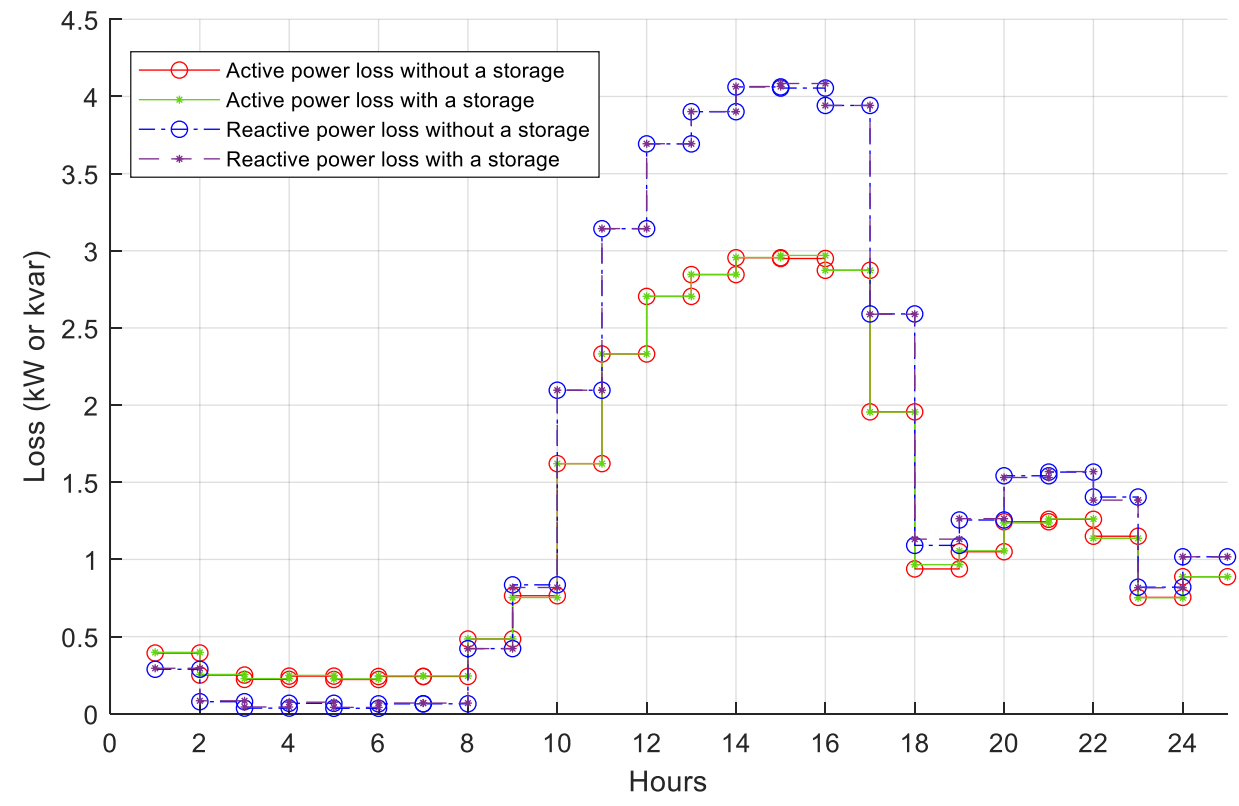

Fig. 14. Active and reactive power losses for the two scenarios.

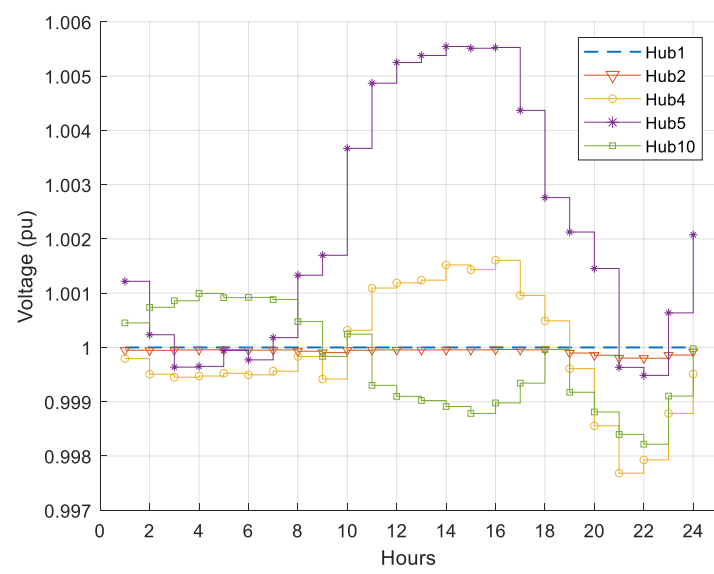

(a)

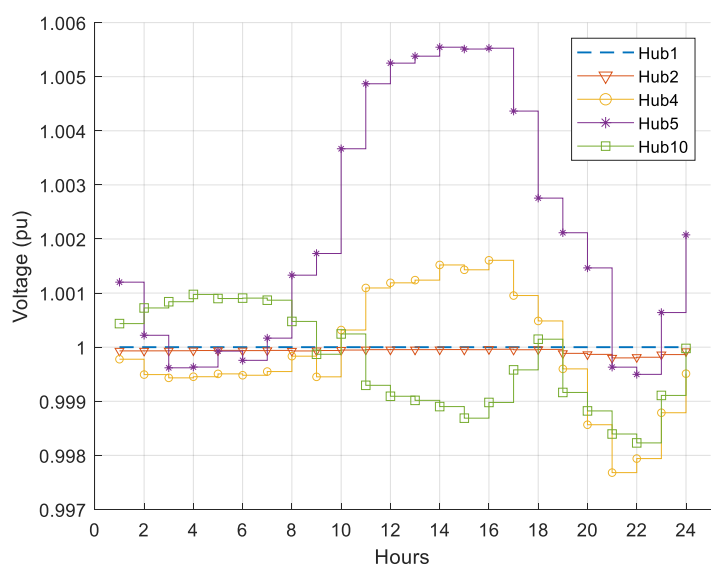

(b)

Fig. 15. Voltage profile at different hubs: (a) without a storage and (b) with a storage.

The root mean-square-values of current flows in each branch are illustrated in Fig. 16. All line currents are far below the maximum limit of 480 A. For better clarity, flows in Line 1-2, Line 2-3 and Line 3-5 are identified with markers. It can be seen that the current profiles in the two scenarios look alike except for Line 1-2. Line 1-2 is a branch through which the system interacts with the external electric grid. The current through Line 1-2 for the two scenarios differ, for example, during the hours at which the thermal storage is charging. As it can be referred from Fig. 7(b), the thermal storage is charging during the hours 1:00 - 7:00 and 17:00 - 19:00. Furthermore, Fig. 12 shows that the system is importing active electricity from the grid in both scenarios during these hours. Thus, a 
storage charging at these hours means additional electricity has to be imported and converted into heat using the HP. This means that the system with a thermal storage is importing more active electricity during these hours (also shown in Fig. 12). This power has no other paths than Line 1-2. As a result, there is higher current flows in Line 1-2 for the system with a thermal storage (Fig. 16(b)) than the system without a thermal storage (Fig. 16(a)).

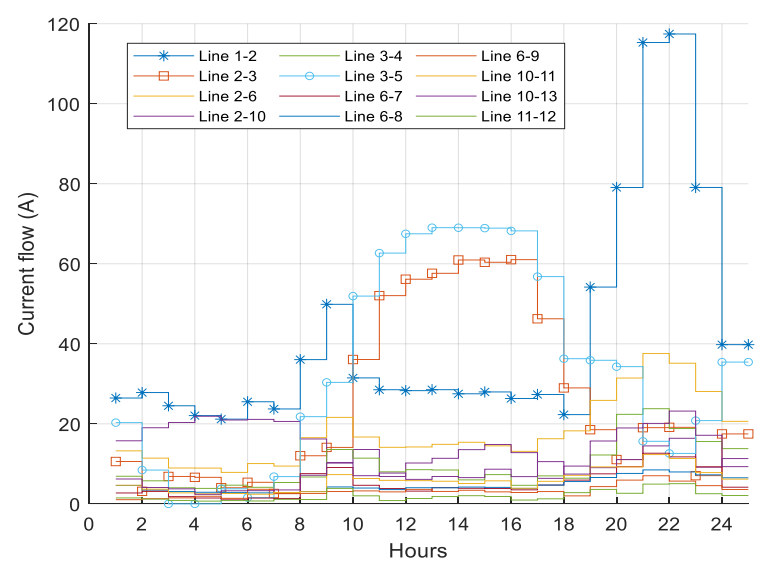

(a)

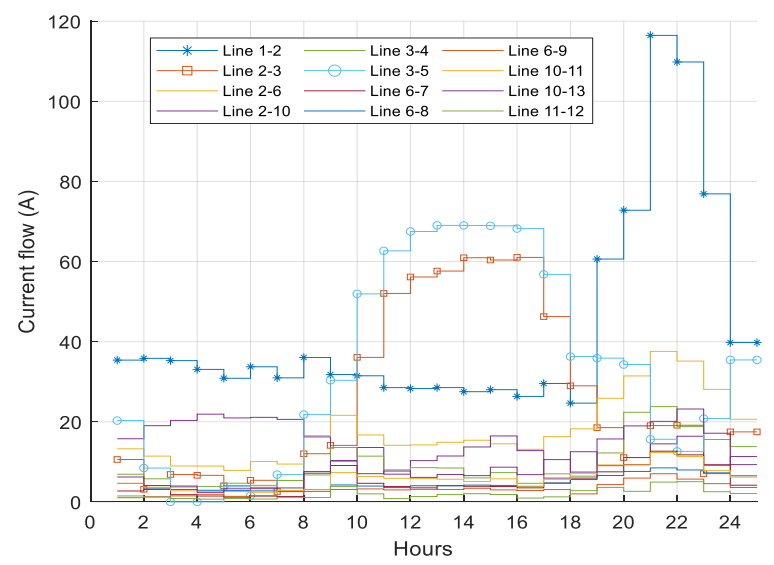

(b)

Fig. 16. Root-mean-square values of current flows through the transmission lines: (a) without a thermal storage and (b) with a thermal storage.

\subsection{Overall system summary}

Table 2 compares the system with and without a thermal storage using key parameters of the overall energy system. One of the results that shows the synergy of the heating and electricity networks is the amount of renewablecurtailment avoided. This is, equivalently, the amount of surplus renewable generation that is used in the system. Out of the 1.176 MWh surplus of electricity generated by the wind power plant (see Section 4.2), $97.90 \%$ (with 7 kWh unused heat) is effectively used in the system without a thermal storage. Similarly, $97.96 \%$ (with zero excess heat) of the curtailment is avoided in the system with a thermal storage. Only $24.66 \mathrm{kWh}$ and $23.98 \mathrm{kWh}$ of surplus wind generations are left unused, respectively (see Table 2).

Table 2 also shows that the total gas consumption is reduced from $10877.5 \mathrm{kWh}$ to $9852.6 \mathrm{kWh}$. This shows, roughly, a reduction of $9.45 \%$ carbon emission. Furthermore, the thermal storage added flexibility by delivering 2094.5 $\mathrm{kWh}$ (about $10.35 \%$ of the total heat demand). Its efficiency can be calculated by taking the ratio of discharged energy to the stored energy, which gives $99.17 \%$.

It can also be seen from Table 2 that the system with a thermal storage exploited the cheap hours of the electricity price signal, as it is indicated by higher imported electricity (both active and reactive) from the grid. 
In agreement with [13], the distribution loss in the heating network with a thermal storage is higher than the system without a storage (see Table 2). The reason is the requirement of higher temperature to charge the storage. The higher electricity consumption of circulation pumps in the system without a storage also indicates the presence of higher flow rate in the pipes caused by lower supply temperatures. However, there is no significant difference on the electricity distribution losses.

In terms of daily operating cost, the system with a thermal storage shows $2.03 \%$ reduction. If it is taken alone, the economical saving for the particular day is not very high. However, considering the added flexibility in peak shaving together with the reduction in gas consumption, the thermal storage is still worthy to consider. Moreover, the results are only for a single day to illustrate the capacity of the tool. Annual optimisation should be combined with financial analysis of the whole system over its entire life span in order to determine the feasibility of thermal storage integration for the given case study, which is outside the scope of this paper.

Table 2: Summary of the optimisation results for the two scenarios.

\begin{tabular}{|l|l|l|}
\hline Performance indicators & Without a thermal storage & With a thermal storage (change) \\
\hline Total heat lost $(\mathrm{kWh})$ & 1900 & $2243(18.1 \% \uparrow)$ \\
\hline Electricity consumption of circulation pumps $(\mathrm{kWh})$ & 35.96 & $22.43(38.1 \% \downarrow)$ \\
\hline Total active electricity lost $(\mathrm{kWh})$ & 30.59 & 30.64 \\
\hline Total active electricity imported $(\mathrm{kWh})$ & 4109.9 & $4392.4(6.9 \% \uparrow)$ \\
\hline Surplus active electricity $(\mathrm{kWh})$ & 24.66 & 23.98 \\
\hline Reactive electricity imported $(\mathrm{kvar})$ & 5077.9 & 5238.4 \\
\hline Unused heat $(\mathrm{kWh})$ & 7.03 & 0.0 \\
\hline Stored heat $(\mathrm{kWh})$ & 0.0 & $2112.1(10.4 \%$ of demand) \\
\hline Discharged heat $(\mathrm{kWh})$ & 0.0 & 2094.5 \\
\hline Gas used at the CHP and boiler $(\mathrm{kWh})$ & $9739.9+1140$ & $9852.6+0\left(9.5 \% \mathrm{CO}_{2} \downarrow\right)$ \\
\hline Total operating cost $(€)$ & 1456.4 & $1426.8(2.03 \% \downarrow)$ \\
\hline
\end{tabular}

\section{Conclusion}

In this paper, the capacity of the EEH modelling approach is demonstrated in capturing the synergy between electricity and heat distribution networks. Optimal electric and heat power flows are determined using a population-based optimisation algorithm. For illustration, a district energy system consisting of a wind power plant, a CHP, a HP, a gas boiler, and a thermal storage is considered together with a variable electricity tariff. Thermo-economic optimisation is then conducted using two scenarios: with and without the consideration of the thermal storage.

- In both scenarios, above $97 \%$ of the surplus production from the wind power plant is effectively used in the system due to the HP that couple the two distribution networks. 
- Integration of the thermal storage, as compared with a system without a thermal storage, increased the heat distribution loss by $18 \%$ due to the rise in the supply temperatures of the DHN while charging.

- The system with a thermal storage imported $6.9 \%$ more active electric power exploiting the cheap hours.

- As a result, the operating cost of the system with a thermal storage is found to be $2.03 \%$ lower.

- $\quad$ The thermal storage also reduced the carbon emission by $9.45 \%$.

- In addition, the thermal storage added flexibility by shifting $10.35 \%$ of the heat demand from the peak hours toward the cheap-electricity hours.

It can be concluded that the EEH modelling and optimization approach is very effective in capturing the synergy between electricity and heat distribution networks and in quantifying the added flexibility that can be obtained from thermal storage integration. The methodology presented in this paper is flexible and easily scalable for larger systems and longer periods.

The paper also sheds light on the integration of smart grid and smart thermal networks. Simulation horizons longer than 24 hours and having uncertainties in the demand and generation forecast can be handled by incorporating an MPC algorithm with a sliding window. Other optimization algorithms can also be applied and compared with the results found in this paper. Further research can be done by considering investment cost at planning phase and variable efficiencies of technologies at partial loading. The methods can also be used as a base to study larger distribution networks with distributed thermal and electrical storage systems.

\section{Acknowledgement}

The research presented is performed within the framework of the Erasmus Mundus Joint Doctorate SELECT+ program 'Environomical Pathways for Sustainable Energy Services' and funded with support from the Education, Audiovisual, and Culture Executive Agency (EACEA) (FPA-2012-0034) of the European Commission. This publication reflects the views only of the author(s), and the Commission cannot be held responsible for any use, which may be made of the information contained therein.

\section{References}

[1] H. Lund, P. A. Østergaard, D. Connolly, and B. V. Mathiesen, 'Smart energy and smart energy systems', Energy, vol. 137, pp. 556-565, Oct. 2017, doi: 10.1016/j.energy.2017.05.123. 
[2] 'EU to fight energy waste with the first Heating and Cooling Strategy', European Commission - European Commission. https://ec.europa.eu/commission/presscorner/detail/en/MEMO_16_311 (accessed Apr. 16, 2020).

[3] F. Levihn, 'CHP and heat pumps to balance renewable power production: Lessons from the district heating network in Stockholm', Energy, Jan. 2017, doi: 10.1016/j.energy.2017.01.118.

[4] K. Kontu, S. Rinne, and S. Junnila, 'Introducing modern heat pumps to existing district heating systems Global lessons from viable decarbonizing of district heating in Finland', Energy, vol. 166, pp. 862-870, Jan. 2019, doi: 10.1016/j.energy.2018.10.077.

[5] R. Lund, D. D. Ilic, and L. Trygg, 'Socioeconomic potential for introducing large-scale heat pumps in district heating in Denmark', J. Clean. Prod., vol. 139, pp. 219-229, Dec. 2016, doi: 10.1016/j.jclepro.2016.07.135.

[6] Eurostat, 'SHARES (Renewables) - Eurostat'. https://ec.europa.eu/eurostat/web/energy/data/shares (accessed Apr. 16, 2020).

[7] F. Calise, F. L. Cappiello, M. Dentice d'Accadia, and M. Vicidomini, 'Smart grid energy district based on the integration of electric vehicles and combined heat and power generation', Energy Convers. Manag., vol. 234, p. 113932, Apr. 2021, doi: 10.1016/j.enconman.2021.113932.

[8] Z. Liu et al., 'Two-phase collaborative optimization and operation strategy for a new distributed energy system that combines multi-energy storage for a nearly zero energy community', Energy Convers. Manag., vol. 230, p. 113800, Feb. 2021, doi: 10.1016/j.enconman.2020.113800.

[9] P. Crespo Del Granado, Z. Pang, and S. W. Wallace, 'Synergy of smart grids and hybrid distributed generation on the value of energy storage', Appl. Energy, vol. 170, pp. 476-488, May 2016, doi: 10.1016/j.apenergy.2016.01.095.

[10] A. R. Razmi and M. Janbaz, 'Exergoeconomic assessment with reliability consideration of a green cogeneration system based on compressed air energy storage (CAES)', Energy Convers. Manag., vol. 204, p. 112320, Jan. 2020, doi: 10.1016/j.enconman.2019.112320.

[11] J. Hennessy, H. Li, F. Wallin, and E. Thorin, 'Flexibility in thermal grids: a review of short-term storage in district heating distribution networks', Energy Procedia, vol. 158, pp. 2430-2434, Feb. 2019, doi: 10.1016/j.egypro.2019.01.302. 
[12] A. Arabkoohsar, A. Behzadi, and N. Nord, 'A highly innovative yet cost-effective multi-generation energy system for net-zero energy buildings', Energy Convers. Manag., vol. 237, p. 114120, Jun. 2021, doi: 10.1016/j.enconman.2021.114120.

[13] A. Vandermeulen, B. van der Heijde, and L. Helsen, 'Controlling district heating and cooling networks to unlock flexibility: A review', Energy, vol. 151, pp. 103-115, May 2018, doi: 10.1016/j.energy.2018.03.034.

[14] 'EnergyPLAN', EnergyPLAN. https://www.energyplan.eu/ (accessed Nov. 22, 2019).

[15] Natural Resources Canada, 'RETScreen', Mar. 10, 2010. https://www.nrcan.gc.ca/energy/softwaretools/7465 (accessed Nov. 05, 2018).

[16] G. Tadesse, 'Feasibility study of small Hydro/PV/Wind hybrid system for off-grid rural electrification in Ethiopia', Addis Ababa University, 2012.

[17] G. T. Ayele, M. T. Mabrouk, P. Haurant, B. Laumert, and B. Lacarrière, 'Optimal placement and sizing of heat pumps and heat only boilers in a coupled electricity and heating networks', Energy, vol. 182, pp. 122-134, Sep. 2019, doi: 10.1016/j.energy.2019.06.018.

[18] M. Arnaudo, M. Topel, and B. Laumert, 'Techno-economic analysis of demand side flexibility to enable the integration of distributed heat pumps within a Swedish neighborhood', Energy, vol. 195, p. 117012, Mar. 2020, doi: 10.1016/j.energy.2020.117012.

[19] HOMER Energy, 'HOMER - Hybrid Renewable and Distributed Generation System Design Software'. https://www.homerenergy.com/ (accessed Nov. 05, 2018).

[20] E. Widl et al., 'Studying the potential of multi-carrier energy distribution grids: A holistic approach', Energy, vol. 153, pp. 519-529, Jun. 2018, doi: 10.1016/j.energy.2018.04.047.

[21] B. K. Das, R. Hassan, M. S. H. K. Tushar, F. Zaman, M. Hasan, and P. Das, 'Techno-economic and environmental assessment of a hybrid renewable energy system using multi-objective genetic algorithm: A case study for remote Island in Bangladesh', Energy Convers. Manag., vol. 230, p. 113823, Feb. 2021, doi: 10.1016/j.enconman.2020.113823.

[22] A. Shabanpour-Haghighi, A. R. Seifi, and T. Niknam, 'A modified teaching-learning based optimization for multi-objective optimal power flow problem’, Energy Convers. Manag., vol. 77, pp. 597-607, Jan. 2014, doi: 10.1016/j.enconman.2013.09.028. 
[23] T. Niknam, M. R. Narimani, J. Aghaei, S. Tabatabaei, and M. Nayeripour, 'Modified Honey Bee Mating Optimisation to solve dynamic optimal power flow considering generator constraints', Transm. Distrib. IET Gener., vol. 5, no. 10, pp. 989-1002, Oct. 2011, doi: 10.1049/iet-gtd.2011.0055.

[24] S. Kansal, V. Kumar, and B. Tyagi, 'Hybrid approach for optimal placement of multiple DGs of multiple types in distribution networks', Int. J. Electr. Power Energy Syst., vol. 75, pp. 226-235, Feb. 2016, doi: 10.1016/j.ijepes.2015.09.002.

[25] J. Allegrini, K. Orehounig, G. Mavromatidis, F. Ruesch, V. Dorer, and R. Evins, 'A review of modelling approaches and tools for the simulation of district-scale energy systems', Renew. Sustain. Energy Rev., vol. 52, pp. 1391-1404, décembre 2015, doi: 10.1016/j.rser.2015.07.123.

[26] B. Leitner, E. Widl, W. Gawlik, and R. Hofmann, 'A method for technical assessment of power-to-heat use cases to couple local district heating and electrical distribution grids', Energy, vol. 182, pp. 729-738, Sep. 2019, doi: 10.1016/j.energy.2019.06.016.

[27] S. Bracco, F. Delfino, F. Pampararo, M. Robba, and M. Rossi, 'A dynamic optimization-based architecture for polygeneration microgrids with tri-generation, renewables, storage systems and electrical vehicles', Energy Convers. Manag., vol. 96, pp. 511-520, May 2015, doi: 10.1016/j.enconman.2015.03.013.

[28] R. Niemi, J. Mikkola, and P. D. Lund, 'Urban energy systems with smart multi-carrier energy networks and renewable energy generation', Renew. Energy, vol. 48, pp. 524-536, décembre 2012, doi: 10.1016/j.renene.2012.05.017.

[29] G. T. Ayele, M. T. Mabrouk, P. Haurant, B. Laumert, B. Lacarrière, and M. Santarelli, 'Electrified district heating networks: a thermo-economic optimisation based on exergy and energy analyses', Int. J. Exergy, vol. 35, no. 1, pp. 100-131, Jan. 2021, doi: 10.1504/IJEX.2021.115088.

[30] J. Li, J. Fang, Q. Zeng, and Z. Chen, 'Optimal operation of the integrated electrical and heating systems to accommodate the intermittent renewable sources', Appl. Energy, vol. 167, pp. 244-254, Apr. 2016, doi: 10.1016/j.apenergy.2015.10.054.

[31] B. Awad, M. Chaudry, J. Wu, and N. Jenkins, 'Integrated optimal power flow for electric power and heat in a MicroGrid', in CIRED 2009 - 20th International Conference and Exhibition on Electricity Distribution - Part 1, Jun. 2009, pp. 1-4.

[32] X. Liu, J. Wu, N. Jenkins, and A. Bagdanavicius, 'Combined analysis of electricity and heat networks', Appl. Energy, vol. 162, pp. 1238-1250, Jan. 2016, doi: 10.1016/j.apenergy.2015.01.102. 
[33] P. F. Boulos, K. E. Lansey, and B. W. Karney, Comprehensive Water Distribution Systems Analysis Handbook for Engineers and Planners. American Water Works Assn, 2006.

[34] X. Liu and P. Mancarella, 'Modelling, assessment and Sankey diagrams of integrated electricity-heat-gas networks in multi-vector district energy systems', Appl. Energy, vol. 167, pp. 336-352, 2016.

[35] A. Shabanpour-Haghighi and A. R. Seifi, 'An Integrated Steady-State Operation Assessment of Electrical, Natural Gas, and District Heating Networks', IEEE Trans. Power Syst., vol. 31, no. 5, pp. 3636-3647, Sep. 2016, doi: 10.1109/TPWRS.2015.2486819.

[36] E. A. Martinez Cesena and P. Mancarella, 'Energy Systems Integration in Smart Districts: Robust Optimisation of Multi-Energy Flows in Integrated Electricity, Heat and Gas Networks', IEEE Trans. Smart Grid, vol. 10, no. 1, pp. 1122-1131, Jan. 2019, doi: 10.1109/TSG.2018.2828146.

[37] H. Khorsand and A. R. Seifi, 'Probabilistic energy flow for multi-carrier energy systems', Renew. Sustain. Energy Rev., vol. 94, pp. 989-997, Oct. 2018, doi: 10.1016/j.rser.2018.07.008.

[38] M. Geidl and G. Andersson, 'Optimal Power Flow of Multiple Energy Carriers', IEEE Trans. Power Syst., vol. 22, no. 1, pp. 145-155, Feb. 2007, doi: 10.1109/TPWRS.2006.888988.

[39] M. Arnold, R. R. Negenborn, G. Andersson, and B. D. Schutter, 'Model-based predictive control applied to multi-carrier energy systems', in 2009 IEEE Power Energy Society General Meeting, Jul. 2009, pp. 18. doi: 10.1109/PES.2009.5275230.

[40] G. T. Ayele, P. Haurant, B. Laumert, and B. Lacarrière, 'An extended energy hub approach for load flow analysis of highly coupled district energy networks: Illustration with electricity and heating', Appl. Energy, vol. 212, pp. 850-867, Feb. 2018, doi: 10.1016/j.apenergy.2017.12.090.

[41] G. T. Ayele, M. T. Mabrouk, P. Haurant, B. Laumert, and B. Lacarrière, 'Pseudo-dynamic simulation on a district energy system made of coupling technologies', presented at the ECOS 2018 - the 31st International Conference on Efficiency, Cost, Optimization, Simulation and Environmental Impact of Energy Systems June 17-22, 2018, Guimarães, PORTUGAL, 2018.

[42] G. T. Ayele, M. T. Mabrouk, P. Haurant, B. Laumert, B. Lacarrière, and M. Santarelli, 'Exergy analysis and thermo-economic optimization of a district heating network with solar-photovoltaic and heat pumps', in Proceedings of ECOS 2019: the 32nd International Conference on Efficiency, Cost, Optimization, Simulation and Environmental Impact of Energy Systems, Wrocław, Poland, Jun. 2019, pp. 1947-1959. 
[43] J. Zheng, Z. Zhou, J. Zhao, and J. Wang, 'Integrated heat and power dispatch truly utilizing thermal inertia of district heating network for wind power integration', Appl. Energy, vol. 211, pp. 865-874, Feb. 2018, doi: 10.1016/j.apenergy.2017.11.080.

[44] J. Salpakari, J. Mikkola, and P. D. Lund, 'Improved flexibility with large-scale variable renewable power in cities through optimal demand side management and power-to-heat conversion', Energy Convers. Manag., vol. 126, pp. 649-661, Oct. 2016, doi: 10.1016/j.enconman.2016.08.041.

[45] A. Campos Celador, M. Odriozola, and J. M. Sala, 'Implications of the modelling of stratified hot water storage tanks in the simulation of CHP plants', Energy Convers. Manag., vol. 52, no. 8, pp. 3018-3026, Aug. 2011, doi: 10.1016/j.enconman.2011.04.015.

[46] 'TRNSYS - Official Website'. https://sel.me.wisc.edu/trnsys/ (accessed Nov. 22, 2019).

[47] J. D. Glover, M. S. Sarma, and T. Overbye, Power System Analysis \& Design, SI Version. Cengage Learning, 2012.

[48] H. Wang, L. Duanmu, X. Li, and R. Lahdelma, 'Optimizing the District Heating Primary Network from the Perspective of Economic-Specific Pressure Loss', Energies, vol. 10, no. 8, p. 1095, Aug. 2017, doi: 10.3390/en10081095.

[49] T. Fang and R. Lahdelma, 'Optimization of combined heat and power production with heat storage based on sliding time window method', Appl. Energy, vol. 162, pp. 723-732, Jan. 2016, doi: 10.1016/j.apenergy.2015.10.135.

[50] 'Thermal energy storage in district heating and cooling systems: A review', Appl. Energy, vol. 252, p. 113474, Oct. 2019, doi: 10.1016/j.apenergy.2019.113474.

[51] J. Kennedy and R. Eberhart, 'Particle swarm optimization', in Proceedings of ICNN'95 - International Conference on Neural Networks, Nov. 1995, vol. 4, pp. 1942-1948 vol.4. doi: 10.1109/ICNN.1995.488968.

[52] Isoplus, 'isoplus: Flexible and rigid pipes and pipeline systems: isoplus - isoplus Fernwärmetechnik'. http://www.isoplus-pipes.com/ (accessed Sep. 03, 2017).

[53] L. L. Grigsby, Electric Power Generation, Transmission, and Distribution. CRC Press, 2018. doi: $10.1201 / 9781315222424$.

[54] 'Centrale de cogénération | Vitobloc 200 Type EM-199/263’, Viessmann, Jun. 25, 2018. https://www.viessmann.fr/fr/chauffage-collectif/cogeneration/centrale-cogeneration/vitobloc-200-em-199263.html (accessed Mar. 17, 2020). 
[55] 'Open Energy Information: Commercial and residential hourly load profile'. https://openei.org/datasets/files/961/pub/ (accessed Jan. 08, 2018).

[56] 'AgriMet Pacific Northwest Region | Bureau of Reclamation'. https://www.usbr.gov/pn/agrimet/webagdayread.html (accessed Dec. 07, 2018). 